\title{
Risk of Cardiovascular Diseases Among Older Breast Cancer Survivors in the United States: A Matched Cohort Study
}

Anthony A. Matthews, PhD 1,2,3; Sharon Peacock Hinton, MPA²; Susannah Stanway, MD; Alexander R. Lyon, PhD ${ }^{5,6}$; Liam Smeeth, $\mathrm{PhD}^{1}$; Krishnan Bhaskaran, $\mathrm{PhD}^{1, \star}$; and Jennifer L. Lund, $\mathrm{PhD}^{2, \star}$

\begin{abstract}
Background: It has been suggested that cardiovascular risks are increased in breast cancer survivors, but few studies have quantified the risks of a range of specific clinically important cardiovascular outcomes in detail. Patients and Methods: Women aged $>65$ years with incident breast cancer from 2004 to 2013 in the SEER-Medicare linked database were matched with 5 cancer-free female counterparts (5:1 ratio). Prevalence of specific cardiovascular outcomes at baseline was measured, then Cox regression was used to calculate hazard ratios (HRs) and 95\% confidence intervals for the risk of individual cardiovascular outcomes during follow-up. Modification of the effect was investigated by time since diagnosis, race/ethnicity, prior cardiovascular disease (CVD), and age. Results: In all, 91,473 women with breast cancer and 454,197 without breast cancer were included. Women with breast cancer had lower baseline prevalence of all CVDs. Compared with cancer-free controls, breast cancer survivors had substantially increased risks of deep vein thrombosis (adjusted $\mathrm{HR}, 1.67 ; 95 \% \mathrm{Cl}, 1.62-1.73 ; 386,484$ person-years of follow-up) and pericarditis (HR, 1.43; 95\% Cl, 1.38-1.49; 390,776 person-years of follow-up); evidence of smaller increased risks of sudden cardiac arrest, arrhythmia, heart failure, and valvular heart disease (adjusted HRs ranging from 1.05-1.09, lower $\mathrm{Cl}$ limits all $\geq 1$ ); and evidence of lower risk of incident angina, myocardial infarction, revascularization, peripheral vascular disease, and stroke (adjusted HRs ranging from $0.89-0.98$, upper $\mathrm{Cl}$ limits all $\leq 1$ ). Increased risks of arrhythmia, heart failure, pericarditis, and deep vein thrombosis persisted $>5$ years after cancer diagnosis. Conclusions: Women with a history of breast cancer were at increased risk of several CVDs, persisting into survivorship. Monitoring and managing cardiovascular risk throughout the long-term follow-up of women diagnosed with breast cancer should be a priority.
\end{abstract}

J Natl Compr Canc Netw 2021;19(3):275-284 doi: $10.6004 /$ jnccn.2020.7629

\footnotetext{
${ }^{1}$ Department of Non-Communicable Diseases Epidemiology, London School of Hygiene and Tropical Medicine, London, United Kingdom; ${ }^{2}$ Department of Epidemiology, Gillings School of Global Public Health, University of North Carolina at Chapel Hill, Chapel Hill, North Carolina; ${ }^{3}$ Unit of Epidemiology, Institute of Environmental Medicine, Karolinska Institutet, Stockholm, Sweden; and ${ }^{4}$ Royal Marsden Hospital, ${ }^{5}$ National Heart and Lung Institute, Imperial College London, and ${ }^{6}$ Royal Brompton Hospital, London, United Kingdom.

*These authors contributed equally to this study.
}

\section{Background}

Breast cancer remains the most common cancer among women worldwide. Earlier detection and the advent of new treatments have facilitated an increase in 5-year survival rate in the United States from $75 \%$ in the 1970 s to $91 \%$ in the 2010s. ${ }^{1}$ In older women diagnosed with breast cancer, there is now a greater likelihood of dying of diseases other than cancer itself. Cardiovascular disease (CVD) is the most frequent cause of noncancer-related death, ${ }^{2,3}$ and there are concerns that overlapping risk factors and cardiotoxicities associated with cancer treatments may increase cardiovascular risk in this population.

There have been few large studies that have assessed the burden of specific CVDs in breast cancer survivors, with most studies focusing on composite cardiovascular outcomes. ${ }^{4-13}$ Before attempting to fully understand the mechanisms behind changes in cardiovascular risk in women diagnosed with breast cancer, there is a pressing need for evidence on associations between breast cancer and clinically specific cardiovascular outcomes. This will pave the way for further exploration of the treatments and risk factors that cause any changes in risk of specific CVDs.

We therefore assessed the prevalence of a range of clinically specific cardiovascular outcomes at breast cancer diagnosis and their incidence after diagnosis among survivors aged $>65$ years compared with similar women without cancer in the United States.

\section{Patients and Methods}

\section{Study Design and Data Source}

We performed a matched cohort study using prospectively collected data from the SEER-Medicare linked claims-based database. The SEER cancer surveillance program currently covers approximately $35 \%$ of the US population. ${ }^{14}$ Medicare Parts A and B provide US government-funded inpatient, physician, and outpatient 
health insurance for individuals aged $\geq 65$ years $^{15}$ and those aged $<65$ years with specific disabilities. The SEERMedicare database is linked using a deterministic algorithm based on name, social security number, sex, and date of birth.

\section{Study Population}

We identified all women aged $>65$ years with an incident stage I-III breast cancer diagnosis in 2004 through 2013. Patients were required to have 1 year of continuous Medicare Parts A and B coverage prior to their diagnosis date to ensure included diagnosis codes reflected incident rather than prevalent CVD. Each patient with breast cancer was matched at diagnosis on year of birth, SEER region (Northeast, South, North Central, West), and race/ethnicity (White, Black, Asian, Hispanic, Native American, other) to up to 5 women with replacement from the 5\% SEER-Medicare noncancer sample who were free of any cancer at the time of their matched patient's diagnosis date (diagnosis date and matched date for the comparison cohort are hereafter referred to as "index date"). Women were excluded if they were diagnosed with any other cancer prior to their index date (excluding nonmelanoma skin cancer).

\section{Exposures}

The main exposure was a diagnosis of breast cancer. Women diagnosed with cancer were compared with a matched noncancer comparison cohort of women.

\section{Outcomes}

The main cardiovascular outcomes of interest were coronary artery disease (angina, myocardial infarction, revascularization procedures, sudden cardiac arrest), peripheral vascular disease, stroke, arrhythmia, heart failure, pericarditis, valvular heart disease, and venous thromboembolism (deep vein thrombosis [DVT], pulmonary embolism). Composite cardiovascular outcomes and individual components of composite outcomes were analyzed separately. Events were identified through a claim with ICD-9 diagnosis and procedure or HCPCS procedure codes in any position (see supplemental eTable 1, available with this article at JNCCN.org).

\section{Covariates}

The following covariates were extracted at index date: age (66-75, >75 85, >85 years), hypertension, diabetes, chronic kidney disease, rheumatoid arthritis, time since index date ( $0-1$ year, $1-3$ years, $3-5$ years, $\geq 5$ years), and current year. Information on cancer stage, grade, and estrogen receptor (ER) or progesterone receptor (PR) status (a record of ER-positive or PR-positive disease indicated a patient was ER/PR-positive) was also extracted for women diagnosed with breast cancer.
All comorbidities were defined during the 1-year period prior to index date and were based on the Klabunde adaptation of the Charlson comorbidity index, ${ }^{16}$ which searches across patients' inpatient and outpatient claims to retain diagnosis codes that are either in the inpatient setting or in 2 outpatient visits separated by $>30$ days.

\section{Statistical Analysis}

The distribution of all covariates at index date between women diagnosed with breast cancer and their cancerfree comparisons was described, including the prevalence of all cardiovascular outcomes in the year before index date. Composite and individual cardiovascular outcomes were analyzed separately. Women diagnosed with the specific cardiovascular outcomes of interest within the year prior to index date were excluded from the analysis of that outcome to ensure incident disease was being measured during follow-up (these were the women previously used to calculate prevalent disease for each cardiovascular outcome at index date). Follow-up began 90 days after index date, because preliminary analyses suggested an acute increased risk of all cardiovascular outcomes in breast cancer survivors compared with their noncancer comparisons during the first 90 days after diagnosis, which is likely caused by women engaging with the healthcare system at the time of their diagnosis and retrospective recording of prevalent CVD (see supplemental eTable 2 for detailed time-stratified analyses). Follow-up ended at earliest of disenrollment from Medicare Parts A or B, death, end of follow-up (December 12, 2014), or the date of cardiovascular outcome of interest.

\section{Primary Analyses}

Number of events and crude incidence rates for each outcome of interest were calculated for women diagnosed with breast cancer and their matched comparisons, along with resulting rate differences. Associations between breast cancer and cardiovascular outcomes were then explored in unadjusted (accounting for matching variables) and adjusted (accounting for all other covariates described above, excluding breast cancer-specific covariates) Cox proportional hazards regression models stratified by matched set (1 model per outcome), with an underlying age timescale. Women with missing data for any covariate $(<1 \%$ overall) were excluded (completecase analysis).

Modification of the effect of breast cancer on cardiovascular risk by the following variables was investigated by fitting interaction terms: time since index date $(0-1,1-3,3-5, \geq 5$ years), race/ethnicity (White, Black, Asian, Hispanic, Native American, other), any cardiovascular disease prior to index date, and age $(66-75,>75-85,>85$ years). The role of cancer stage, 


\section{Table 1. Baseline Characteristics of Study Cohorts}

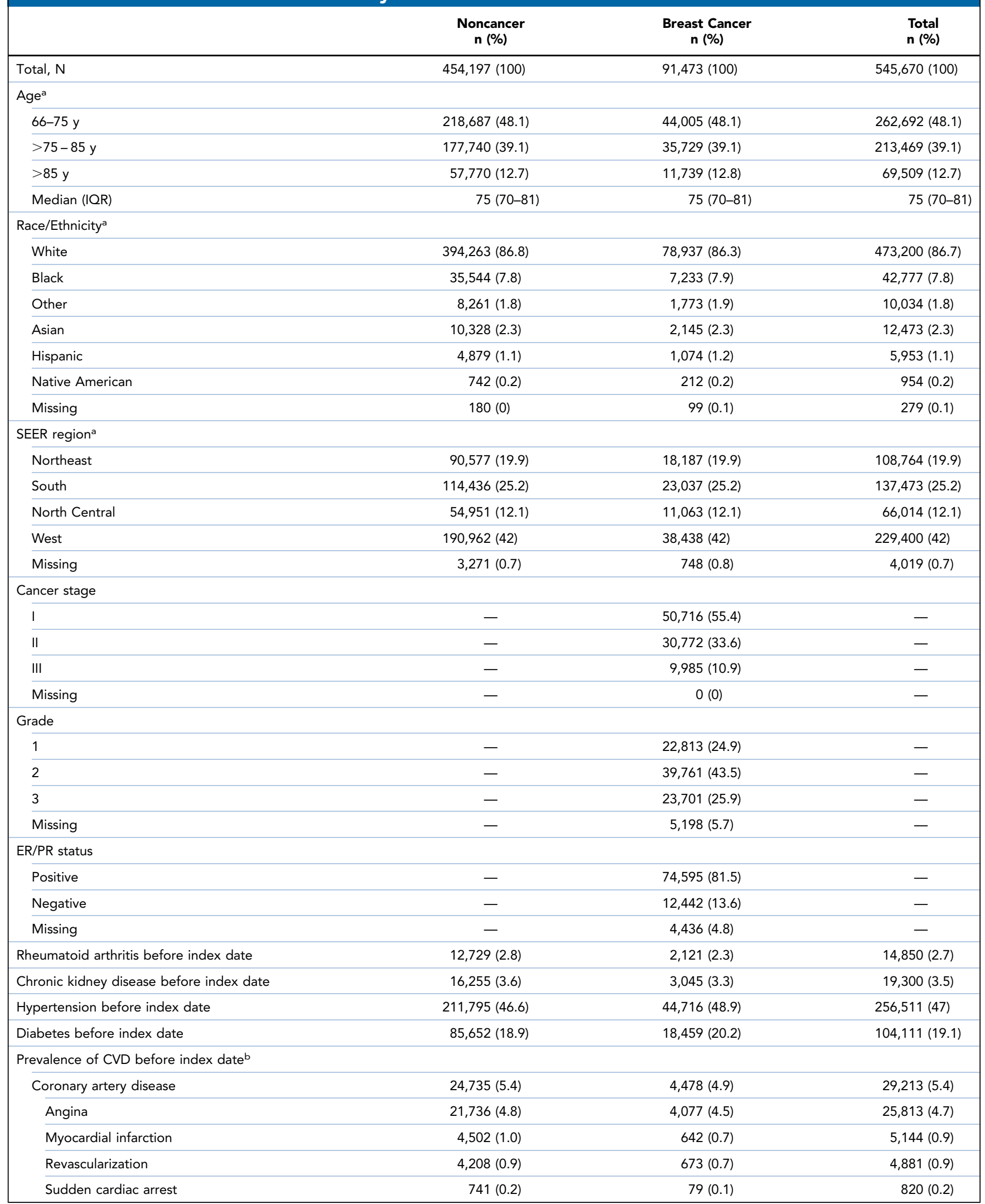




\begin{tabular}{|c|c|c|c|}
\hline & $\begin{array}{c}\text { Noncancer } \\
\text { n (\%) }\end{array}$ & $\begin{array}{c}\text { Breast Cancer } \\
\text { n (\%) }\end{array}$ & $\begin{array}{l}\text { Total } \\
\text { n (\%) }\end{array}$ \\
\hline \multicolumn{4}{|c|}{ Prevalence of CVD before index date (cont.) ${ }^{b}$} \\
\hline Peripheral vascular disease & $33,381(7.3)$ & $6,063(6.6)$ & $39,444(7.2)$ \\
\hline Stroke & $35,534(7.8)$ & $6,351(6.9)$ & $41,885(7.7)$ \\
\hline Arrhythmia & $54,834(12.1)$ & $11,110(12.1)$ & $65,944(12.1)$ \\
\hline Heart failure & $57,771(12.7)$ & $10,738(11.7)$ & $68,509(12.6)$ \\
\hline Pericarditis & $2,092(0.5)$ & $412(0.5)$ & $2,504(0.5)$ \\
\hline Valvular heart disease & $58,674(12.9)$ & $11,683(12.8)$ & $70,357(12.9)$ \\
\hline Venous thromboembolism & $4,180(0.9)$ & $788(0.9)$ & $4,968(0.9)$ \\
\hline Deep vein thrombosis & $3,875(0.9)$ & $736(0.8)$ & $4,611(0.8)$ \\
\hline Pulmonary embolism & $379(0.1)$ & $64(0.1)$ & $443(0.1)$ \\
\hline
\end{tabular}

Abbreviations: CVD, cardiovascular disease; $E R$, estrogen receptor; $I Q R$, interquartile range; PR, progesterone receptor. aMatching variables.

bOne year before index date.

grade, and ER/PR receptor status was also explored by subdividing those diagnosed with breast cancer according to their stage, grade, and ER/PR status, and estimating separate hazard ratios (HRs) for each group.

\section{Flexible Parametric Models}

To model differing effects of a breast cancer diagnosis on cardiovascular risk over time, flexible parametric survival models were built for each outcome, using time since index date as the timescale. ${ }^{17}$ These models used cubic splines to model the cumulative hazard, allowing for the specification of time-dependent covariate effects. All models used a spline with 3 knots placed at 1, 3, and 5 years after index date, and were adjusted for all covariates.

\section{Sensitivity Analyses}

Primary analyses were repeated using only inpatient claims to define cardiovascular outcomes, which may be more reliable when defining incident outcomes in comparison with outpatient claims.

\section{Results}

A total of 545,670 women aged $>65$ years were included in the study population: $91,473(17 \%)$ with a breast cancer diagnosis and 454,197 (83\%) without cancer (Table 1). The comorbidity profile of these women was generally similar, with those diagnosed with breast cancer having a slightly higher prevalence of hypertension and diabetes at diagnosis compared with their noncancer counterparts. The prevalence of all CVDs was slightly lower in women diagnosed with breast cancer, but differences were generally small.

\section{Primary Analyses}

Mean follow-up per person ranged from 3.73 years in the valvular heart disease analysis to 4.50 years in the pulmonary embolism analysis. Incident rates of cardiovascular outcomes in those diagnosed with breast cancer ranged from 0.89 events per 1,000 person-years in the pulmonary embolism analysis to 80.74 events per 1,000 person-years in the arrhythmia analysis (Table 2). In the noncancer comparisons, incident rates ranged from 0.86 per 1,000 person-years in the pulmonary embolism analysis to 74.98 per 1,000 person-years in the arrhythmia analysis (Table 2). After adjustment for all covariates and excluding the first 90 days of follow-up, there was evidence of a slightly lower risk of angina, myocardial infarction, revascularization, peripheral vascular disease, and stroke in women diagnosed with breast cancer compared with the matched comparison cohort (Table 2). Adjusted HRs ranged from 0.89 (95\% CI, 0.85-0.92) for revascularization to 0.98 (95\% CI, $0.97-1.00$ ) for stroke. There was evidence of an increased risk of sudden cardiac arrest, arrhythmia, heart failure, pericarditis, valvular heart disease, and DVT in women diagnosed with breast cancer compared with the noncancer cohort. Adjusted HRs ranged from 1.05 (95\% CI, 1.01-1.10) for sudden cardiac arrest to 1.67 (95\% CI, 1.62-1.73) for DVT.

\section{Variation Over Time and Effect Measure Modification}

There was evidence of effect measure modification by time since index date for all outcomes except pulmonary embolism (Table 3). A breast cancer diagnosis was associated with a lower risk of angina, myocardial infarction, revascularization, peripheral vascular disease, and stroke in the years soon after index date (Figure 1), but the direction of association then changed after 5 years for myocardial infarction and stroke. However, a breast cancer diagnosis was associated with an increased risk of sudden cardiac arrest, arrhythmia, heart failure, 


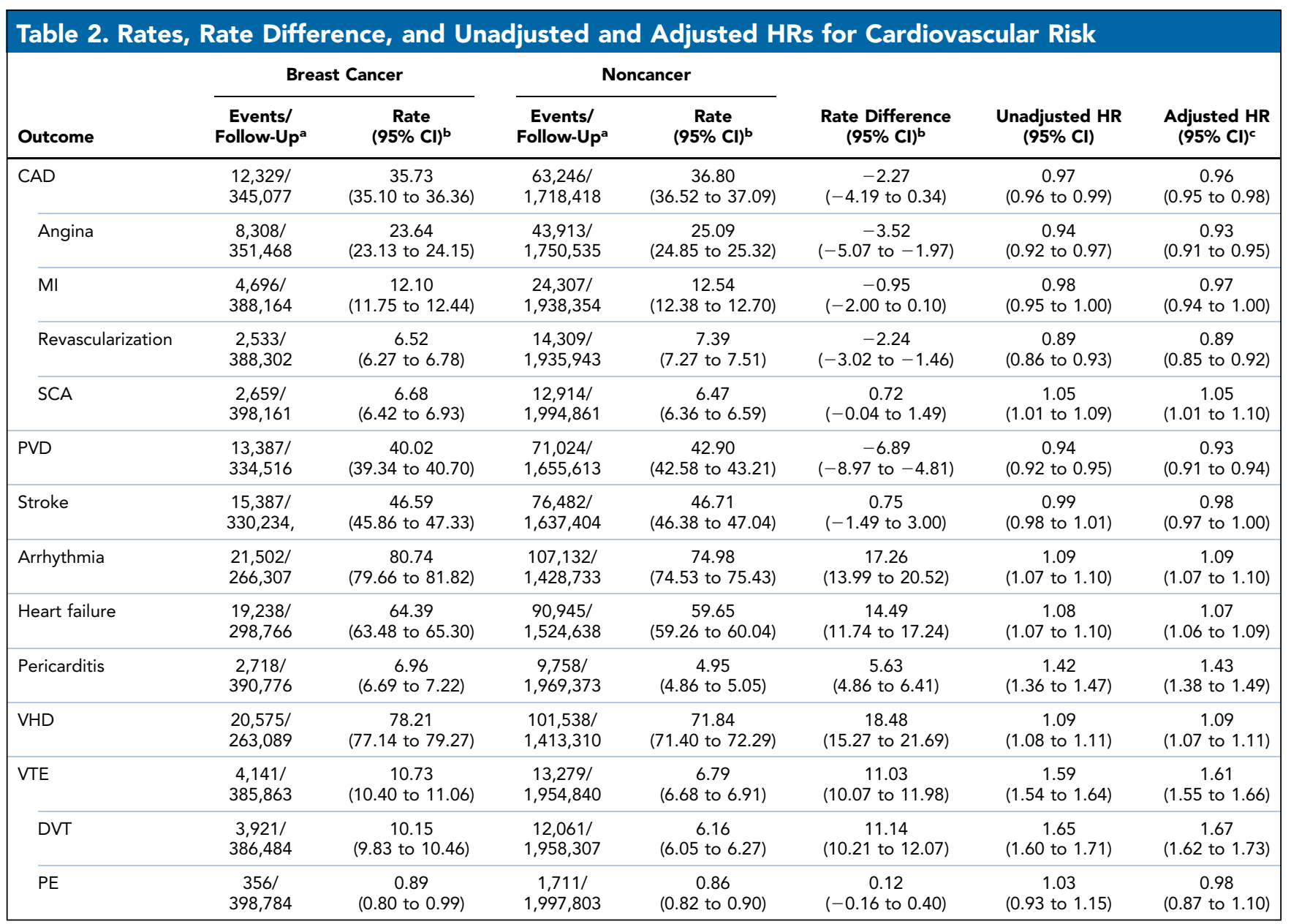

Abbreviations: CAD, coronary artery disease; DVT, deep vein thrombosis; HR, hazard ratio; Ml, myocardial infarction; PE, pulmonary embolism; PVD, peripheral vascular disease; SCA, sudden cardiac arrest; VHD, valvular heart disease; VTE, venous thromboembolism.

aperson-years.

bPer 1,000 person-years.

'Adjusted for age, race/ethnicity, SEER region, time since index, current year, rheumatoid arthritis, chronic kidney disease, hypertension, diabetes, and any other cardiovascular disease prior to index date

(other than the disease of interest).

pericarditis, valvular heart disease, and DVT in the years soon after index date, which was most pronounced in the first year, but continued to show evidence of an increased risk after 5 years (except sudden cardiac arrest and valvular heart disease). Similar patterns were seen in flexible parametric survival models, in which variation in HRs over time were fitted as a smooth function (Figure 1).

There was also evidence of effect measure modification by race/ethnicity for the composite coronary artery disease and venous thromboembolic outcomes, and for myocardial infarction and DVT (Table 4, supplemental eTable 3). A breast cancer diagnosis was associated with an increased risk of coronary artery disease and myocardial infarction in Black women (adjusted HRs, 1.08; 95\% CI, 1.02-1.15. and 1.10; 95\% CI, $1.00-1.22$, respectively), but a decreased risk of these in
White women (adjusted HRs, 0.95; 95\% CI, 0.94-0.97, and $0.96 ; 95 \%$ CI, $0.93-0.99$, respectively). A diagnosis of breast cancer was associated with an increased risk of both the composite venous thromboembolism outcome and DVT in all races/ethnicities, but there was a larger increased risk of both outcomes in Black versus White women.

There was evidence of effect measure modification by prior CVD for many of the outcomes (supplemental eTable 4), with higher relative risks among those without a prior cardiovascular diagnosis. There was also evidence of effect measure modification by age for several cardiovascular outcomes (supplemental eTable 5), with higher relative risks among younger groups (other than for stroke).

When those diagnosed with breast cancer were subdivided into stage, grade, and ER/PR status, there was consistently a greater risk of all cardiovascular outcomes in those diagnosed with stage III (vs earlier stage), grade 3 


\begin{tabular}{|c|c|c|c|}
\hline Outcome & $\begin{array}{l}\text { Time Since } \\
\text { Index Date }\end{array}$ & $\begin{array}{l}\text { Adjusted HRa } \\
(95 \% \mathrm{Cl})\end{array}$ & $\begin{array}{l}P \text { Value for } \\
\text { Interaction }\end{array}$ \\
\hline \multirow[t]{4}{*}{ CAD } & $0-1$ y & $0.92(0.89-0.96)$ & .02 \\
\hline & $1-3 y$ & $0.97(0.94-1.00)$ & \\
\hline & $3-5 y$ & $0.96(0.92-1.00)$ & \\
\hline & $\geq 5 y$ & $1.02(0.97-1.06)$ & \\
\hline \multirow[t]{4}{*}{ Angina } & $0-1$ y & $0.87(0.83-0.91)$ & $<.01$ \\
\hline & $1-3 y$ & $0.94(0.90-0.97)$ & \\
\hline & $3-5 y$ & $0.95(0.90-1.00)$ & \\
\hline & $\geq 5 y$ & $0.99(0.94-1.05)$ & \\
\hline \multirow[t]{4}{*}{ MI } & $0-1$ y & $0.96(0.89-1.04)$ & $<.01$ \\
\hline & $1-3 y$ & $0.94(0.89-0.99)$ & \\
\hline & $3-5 y$ & $0.91(0.86-0.97)$ & \\
\hline & $\geq 5 y$ & $1.09(1.02-1.16)$ & \\
\hline \multirow[t]{4}{*}{ Revascularization } & $0-1$ y & $0.74(0.66-0.82)$ & $<.01$ \\
\hline & $1-3 y$ & $0.92(0.86-0.98)$ & \\
\hline & $3-5 y$ & $0.88(0.81-0.96)$ & \\
\hline & $\geq 5 y$ & $0.98(0.89-1.07)$ & \\
\hline \multirow[t]{4}{*}{ SCA } & $0-1$ y & $1.20(1.09-1.33)$ & .06 \\
\hline & $1-3 y$ & $1.04(0.97-1.11)$ & \\
\hline & $3-5 y$ & $1.02(0.94-1.11)$ & \\
\hline & $\geq 5 y$ & $1.02(0.94-1.11)$ & \\
\hline \multirow[t]{4}{*}{ PVD } & $0-1$ y & $0.82(0.79-0.86)$ & $<.01$ \\
\hline & $1-3 y$ & $0.92(0.89-0.94)$ & \\
\hline & $3-5 y$ & $0.96(0.92-1.00)$ & \\
\hline & $\geq 5 y$ & $1.03(0.99-1.08)$ & \\
\hline \multirow[t]{4}{*}{ Stroke } & $0-1$ y & $0.94(0.91-0.98)$ & $<.01$ \\
\hline & $1-3 y$ & $0.96(0.94-0.99)$ & \\
\hline & $3-5 y$ & $1.02(0.98-1.06)$ & \\
\hline & $\geq 5 y$ & $1.05(1.01-1.09)$ & \\
\hline \multirow[t]{4}{*}{ Arrhythmia } & $0-1$ y & $1.15(1.12-1.19)$ & $<.01$ \\
\hline & $1-3 y$ & $1.05(1.03-1.08)$ & \\
\hline & $3-5 y$ & $1.10(1.07-1.14)$ & \\
\hline & $\geq 5 y$ & $1.07(1.03-1.11)$ & \\
\hline \multirow[t]{4}{*}{ Heart failure } & $0-1$ y & $1.17(1.13-1.20)$ & $<.01$ \\
\hline & $1-3 y$ & $1.03(1.01-1.06)$ & \\
\hline & $3-5 y$ & 1.05 (1.01-1.09) & \\
\hline & $\geq 5 y$ & $1.07(1.03-1.11)$ & \\
\hline
\end{tabular}

(continued)

(vs lower grade), and ER/PR-negative (vs ER/PR-positive) breast cancer compared with their noncancer comparisons (supplemental eTables 6-8).

\section{Sensitivity Analyses}

There were small differences in the effect estimates for all cardiovascular outcomes when comparing the results for the primary analyses and analyses using only inpatient claims (supplemental eTable 9), but differences did not materially change conclusions.

\section{Discussion}

In this large US cancer registry-based study of women aged $>65$ years with breast cancer versus a noncancer

\begin{tabular}{|c|c|c|c|}
\hline Outcome & $\begin{array}{l}\text { Time Since } \\
\text { Index Date }\end{array}$ & $\begin{array}{c}\text { Adjusted HR } \\
(95 \% \mathrm{Cl})\end{array}$ & $\begin{array}{l}P \text { Value for } \\
\text { Interaction }\end{array}$ \\
\hline Pericarditis & $\begin{array}{l}0-1 y \\
1-3 y \\
3-5 y \\
\geq 5 y\end{array}$ & $\begin{array}{l}2.10(1.92-2.30) \\
1.32(1.23-1.41) \\
1.39(1.28-1.52) \\
1.23(1.13-1.35)\end{array}$ & .00 \\
\hline VHD & $\begin{array}{l}0-1 y \\
1-3 y \\
3-5 y \\
\geq 5 y\end{array}$ & $\begin{array}{l}1.28(1.24-1.32) \\
1.05(1.02-1.07) \\
1.01(0.98-1.05) \\
1.02(0.98-1.06)\end{array}$ & $<.01$ \\
\hline VTE & $\begin{array}{l}0-1 y \\
1-3 y \\
3-5 y \\
\geq 5 y\end{array}$ & $\begin{array}{l}2.24(2.08-2.40) \\
1.52(1.44-1.61) \\
1.52(1.41-1.63) \\
1.35(1.25-1.46)\end{array}$ & $<.01$ \\
\hline DVT & $\begin{array}{l}0-1 y \\
1-3 y \\
3-5 y \\
\geq 5 y\end{array}$ & $\begin{array}{l}2.39(2.22-2.57) \\
1.56(1.48-1.66) \\
1.60(1.48-1.72) \\
1.39(1.28-1.50)\end{array}$ & $<.01$ \\
\hline PE & $\begin{array}{l}0-1 y \\
1-3 y \\
3-5 y \\
\geq 5 y\end{array}$ & $\begin{array}{l}1.05(0.80-1.38) \\
1.03(0.85-1.26) \\
0.89(0.71-1.12) \\
0.95(0.75-1.19)\end{array}$ & .74 \\
\hline
\end{tabular}

Abbreviations: CAD, coronary artery disease; DVT, deep vein thrombosis; $H R$, hazard ratio; $\mathrm{Ml}$, myocardial infarction; $\mathrm{PE}$, pulmonary embolism; PVD, peripheral vascular disease; SCA, sudden cardiac arrest; VHD, valvular heart disease; VTE, venous thromboembolism.

aAdjusted for age, SEER region, time since index, current year, rheumatoid arthritis, chronic kidney disease, hypertension, diabetes, and any other cardiovascular disease prior to index date (other than the disease of interest).

comparison cohort, evidence was seen of an increased risk of incident sudden cardiac arrest, arrhythmia, heart failure, pericarditis, valvular heart disease, and DVT during follow-up among those diagnosed with breast cancer compared with their matched noncancer comparisons, despite little difference between the groups in the prevalence of preexisting CVD at baseline. Although these effects were most pronounced in the first year, risks remained elevated for arrhythmia, heart failure, pericarditis, and DVT after 5 years. There was evidence of a decreased risk of incident angina, myocardial infarction, revascularization, peripheral vascular disease, and stroke in breast cancer survivors, but this was not constant over time. The cardiovascular risk during follow-up was consistently higher in Black women diagnosed with breast cancer compared with White women, regardless of whether there was an overall increased or decreased risk of outcomes over all of follow-up, which is consistent with racial differences in overall cardiovascular risk in the United States. ${ }^{18}$ Finally, there was consistently a greater risk of all cardiovascular outcomes in those diagnosed with stage III, grade 3 , and ER/PR-negative breast cancer, which is likely a reflection of the more aggressive cancer treatment regimens used in these subtypes. 

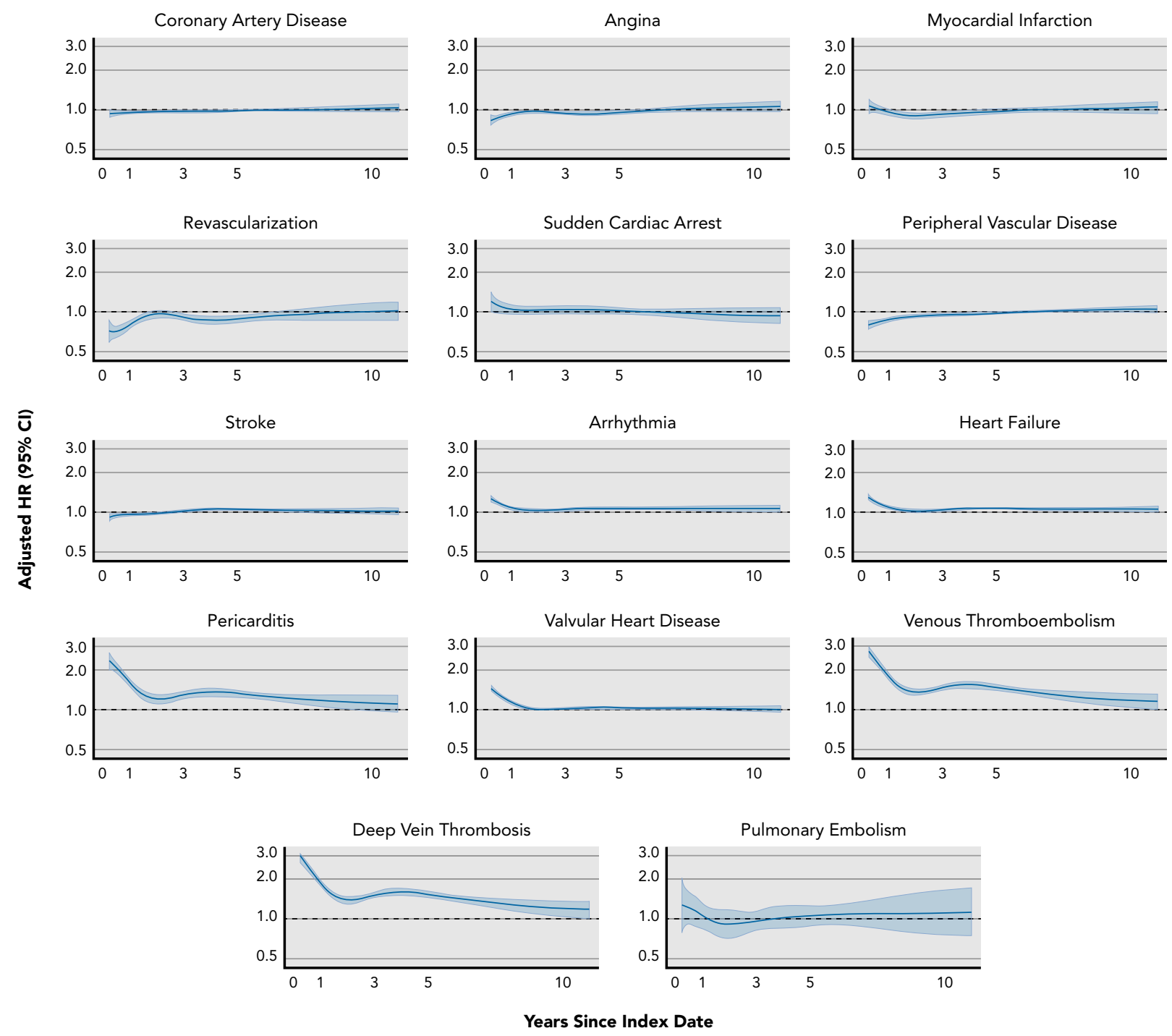

Figure 1. Flexible parametric models for the association between breast cancer and a range of cardiovascular outcomes over time since index date. Abbreviation: $H R$, hazard ratio.

\section{Comparison With Other Studies}

Several studies have suggested an increased risk of heart failure in older women with a breast cancer diagnosis (relative risks ranged from $0.98-1.35),{ }^{4-6,13}$ which is similar to our result over the whole time period (adjusted HR, 1.07; 95\% CI, 1.06-1.09). However, we additionally suggest that this effect is sustained after 5 years, which has also been shown in Canadian and UK populations. ${ }^{4,13}$ Furthermore, although studies have reported both an increased and a decreased risk of stroke in breast cancer survivors, ${ }^{4-6,13}$ none have suggested that the risk of stroke in those diagnosed with breast cancer compared with noncancer comparisons changes as time after breast cancer diagnosis increases, with a decreased risk in the time shortly after breast cancer, followed by an increased risk after 5 years, as we have shown. Our results dissect the previous evidence for valvular heart disease, with one study reporting a larger estimated effect and another reporting no association. ${ }^{6,13}$ Previous studies estimating risk of coronary artery disease in individuals with a breast cancer diagnosis have reported conflicting results, and generally had little precision to detect any effects. ${ }^{4-6,9}$ However, a recent study in the United Kingdom reported a decreased risk of coronary artery disease in women with breast cancer compared with cancer-free comparisons (HR, 0.84; 95\% CI, 0.77-0.92), ${ }^{13}$ which is similar, but more protective, compared with results estimated in this population in the United States (HR, 0.96; 95\% CI, 0.95-0.98). Several studies have reported an increased risk of venous thromboembolism in women with a breast cancer 
diagnosis compared with those without, ${ }^{8,10,13}$ with 2 reporting a similar sustained increased risk after 5 years.

\section{Potential Reasons for Differences in \\ Cardiovascular Risk}

It is likely that those diagnosed with breast cancer have a higher body mass index, are more likely to smoke, ${ }^{19}$ consume more alcohol, ${ }^{20}$ have a sedentary lifestyle, ${ }^{21}$ and have metabolic syndrome, ${ }^{22}$ which are all known to increase cardiovascular risk. ${ }^{23-27}$ The results showing an increased risk of outcome in those with a breast cancer diagnosis could therefore be partly explained by differences in modifiable risk factors, but this will not explain any apparent reduced cardiovascular risk associated with a breast cancer diagnosis.

Effects of cancer treatments could also contribute to the differences in cardiovascular risk. For example, all doses of the anthracyclines doxorubicin and epirubicin are known to increase risk of heart failure, arrhythmias, atrial fibrillation, and left ventricular dysfunction ${ }^{28-30}$; there is also a known association between trastuzumab and heart failure. ${ }^{31}$ Myocardial infarction and arrhythmias are reported as side effects of 5-fluorouracil, ${ }^{32-34}$ but any effects are thought to be acute, with long-term cardiotoxicity uncommon. ${ }^{35}$ It has been suggested that users of the hormone therapy tamoxifen are at an increased risk of venous thromboembolism compared with aromatase inhibitor users, but at a decreased risk of other cardiovascular outcomes, such as coronary heart disease. ${ }^{36-38}$ The increased risk of venous thromboembolism in tamoxifen users is likely a key driver for the increased risk of DVT seen in patients with breast cancer compared with the noncancer comparison cohort, and the decreasing risk over time suggests that this adverse effect is likely to occur early in treatment. A reduced risk of coronary artery diseases in tamoxifen users may also explain the low risk of such outcomes soon after breast cancer diagnosis that returns to neutral after 5 years, driven by women who undergo treatment regimens in which tamoxifen is stopped after 5 years, and hence any protective effect is removed. The increasing risk of coronary artery diseases over time may also be partially attributed to the dose-dependent linear increase in risk for major coronary events due to exposure to ionizing radiation. ${ }^{39}$ Finally, cardiovascular events do not occur independently and may influence each other. For example, arrhythmias may be due to symptomatic heart failure or ischemia and may contribute to embolic stroke over time.

Although information on administered or dispensed breast cancer treatments is available in claims data, we did not adjust for these in our analysis. This is because the aim of the analysis was to describe the incidence of a range of cardiovascular diseases in women with breast

\begin{tabular}{|c|c|c|c|}
\hline Outcome & Race/Ethnicity & $\begin{array}{c}\text { Adjusted } \mathbf{H R}^{\mathrm{a}} \\
(95 \% \mathrm{Cl})\end{array}$ & $\begin{array}{l}P \text { Value for } \\
\text { Interaction }\end{array}$ \\
\hline \multirow[t]{6}{*}{ CAD } & White & $0.95(0.94-0.97)$ & \multirow[t]{6}{*}{$<.01$} \\
\hline & Black & $1.08(1.02-1.15)$ & \\
\hline & Other & $0.94(0.81-1.10)$ & \\
\hline & Asian & $1.00(0.88-1.14)$ & \\
\hline & Hispanic & $0.90(0.76-1.06)$ & \\
\hline & Native American & $1.12(0.74-1.69)$ & \\
\hline \multirow[t]{6}{*}{$\mathrm{Ml}$} & White & $0.96(0.93-0.99)$ & \multirow[t]{6}{*}{.04} \\
\hline & Black & $1.10(1.00-1.22)$ & \\
\hline & Other & $1.04(0.81-1.33)$ & \\
\hline & Asian & $1.08(0.87-1.33)$ & \\
\hline & Hispanic & $0.78(0.58-1.05)$ & \\
\hline & Native American & $1.44(0.66-3.11)$ & \\
\hline \multirow[t]{6}{*}{ VTE } & White & $1.58(1.52-1.64)$ & \multirow[t]{6}{*}{.02} \\
\hline & Black & $1.83(1.65-2.04)$ & \\
\hline & Other & $2.41(1.71-3.39)$ & \\
\hline & Asian & 1.49 (1.09-2.05) & \\
\hline & Hispanic & $1.53(1.05-2.24)$ & \\
\hline & Native American & $2.15(0.83-5.57)$ & \\
\hline \multirow[t]{6}{*}{ DVT } & White & $1.65(1.59-1.71)$ & \multirow[t]{6}{*}{.03} \\
\hline & Black & $1.84(1.65-2.05)$ & \\
\hline & Other & $2.84(1.96-4.10)$ & \\
\hline & Asian & $1.54(1.09-2.18)$ & \\
\hline & Hispanic & $1.62(1.11-2.36)$ & \\
\hline & Native American & $2.16(0.84-5.56)$ & \\
\hline
\end{tabular}

Abbreviations: CAD, coronary artery disease; DVT, deep vein thrombosis; $H R$, hazard ratio; $\mathrm{MI}$, myocardial infarction; VTE, venous thromboembolism. aAdjusted for age, SEER region, time since index, current year, rheumatoid arthritis, chronic kidney disease, hypertension, diabetes, and any other cardiovascular disease prior to index date (other than the disease of interest).

cancer compared with similar women without cancer based on their characteristics at start of follow-up, rather than make inference about the causal reasons behind any difference in cardiovascular risk between these women. However, results from this study will inform further causal exploration of the treatments and risk factors that alter the risk of specific CVDs in women with breast cancer.

Finally, it is possible that the lower prevalence of CVDs prior to start of follow-up in those diagnosed with breast cancer may be the result of unmeasured confounding by socioeconomic status, given the known increased risk of breast cancer incidence in women with a higher socioeconomic status. ${ }^{40}$ The difference could also be due to differential ascertainment of CVD prior to start of follow-up; that is, leading up to breast cancer diagnosis, healthcare may be focused on the cancer, but once a cancer treatment plan is set, other conditions may come into focus and be retrospectively diagnosed (eg, patient may resume care with primary care and cardiology). This differential ascertainment of CVDs may also explain the increase in valvular heart disease shortly after breast cancer diagnosis, because there is no clear biologic rationale for such an effect. However, 
further study is needed to understand completely the reasons for differences in CVD prior to and soon after the start of follow-up.

\section{Strengths and Limitations}

SEER-Medicare includes a large, diverse population of older women diagnosed with breast cancer, along with a matched noncancer comparison cohort, and therefore results are likely to be generalizable to women aged $>65$ years diagnosed with breast cancer in both the United States and other developed countries.

A limitation of using this database is that modifiable risk factors for both breast cancer and CVD, such as body mass index, smoking, alcohol, a sedentary lifestyle, and hyperlipidemia, are either not captured or poorly captured in SEER-Medicare. ${ }^{41,42}$ However, the aim of these analyses was to assess the overall cardiovascular burden in patients with breast cancer versus those without cancer, and not an attempt to infer any causal relationship between a breast cancer diagnosis and cardiovascular morbidity. Furthermore, data on HER2 status were not available because collection was not required until 2010 in SEER, and therefore there was a high degree of incompleteness. Finally, diagnoses of breast cancer, CVDs, and other measured clinical conditions relied on correct specification of ICD-10 codes, and as with any coding system, codes may be inconsistently or incorrectly used.

\section{Conclusions}

There is evidence of increased risks of several cardiovascular outcomes in older women diagnosed with breast cancer in the United States compared with similar women without cancer, with increased risks of arrhythmia, heart failure, pericarditis, and DVT persisting several years after diagnosis. Our results highlight the importance of periodic cardiovascular evaluation of women diagnosed with breast cancer to ensure adequate management of cardiovascular risk.

\section{Acknowledgments}

The authors acknowledge the efforts of NCI; the Centers for Medicare \& Medicaid Services Office of Research, Development, and Information; Information Management Services, Inc.; and the SEER Program tumor registries in the creation of the SEER-Medicare database.

Submitted January 15, 2020; accepted for publication July 24, 2020. Published online January 5, 2021

Author contributions: Study design: Matthews, Bhaskaran, Lund. Data extraction: Matthews, Hinton. Data analysis: Matthews. Manuscript preparation-first draft: Matthews. Critical revision and final approval: All authors

Disclosures: Dr. Stanway has disclosed that she receives consulting fees from Roche, Clinigen, Eli Lilly, and Novartis. Dr. Lyon has disclosed that he receives consulting fees from Servier, Novartis, Pfizer, Roche, Ferring Pharmaceuticals, Clinigen Group, Boehringer Ingelheim, Amgen, Eli Lily, and Bristol-Myers Squibb. Dr. Smeeth has disclosed that he has received grant/research support from Wellcome, and grant/research support and consulting fees from GlaxoSmithKline. Dr. Bhaskaran has disclosed that he has received grant/research support from Wellcome Trust and the Royal Society. Dr. Lund has disclosed that her spouse is employed by GlaxoSmithKline. The remaining authors have disclosed that they have financial consideration from any person or organization to support the preparation, analysis, results, or discussion of this article.

Funding: This work was supported by a Sir Henry Dale Fellowship jointly funded by the Wellcome Trust and the Royal Society (107731/Z/15/Z) held by Dr. Bhaskaran

The database infrastructure used for this project was supported through the University of North Carolina Clinical and Translational Science Award (UL1TR001111) and the UNC Lineberger Comprehensive Cancer Center, University Cancer Research Fund via the State of North Carolina. The collection of cancer incidence data used in this study was supported by the California Department of Public Health as part of the statewide cancer reporting program mandated by California Health and Safety Code Section 103885; NCl's SEER Program under contract HHSN261201000140C awarded to the Cancer Prevention Institute of California, contract HHSN261201000035C awarded to the University of Southern California, and contract HHSN261201000034C awarded to the Public Health Institute; and the CDC's National Program of Cancer Registries, under agreement U58DP003862-01 awarded to the California Department of Public Health.

Disclaimers: The ideas and opinions expressed herein are those of the author(s), and endorsement by the State of California Department of Public Health, $\mathrm{NCl}$, and $\mathrm{CDC}$ or their Contractors and Subcontractors is not intended nor should be inferred. The interpretation and reporting of data from the linked SEER-Medicare database are the sole responsibility of the authors. Funders of this study had no role in the study design, data analysis, or writing of this report.

Correspondence: Anthony A. Matthews, PhD, Unit of Epidemiology, Karolinska Institutet, Nobels väg 13, 17165 Solna, Sweden.

Email: anthony.matthews@ki.se

\section{References}

1. American Cancer Society. Cancer Facts \& Figures 2018. Atlanta, GA: American Cancer Society; 2018.

2. Chapman JA, Meng D, Shepherd L, et al. Competing causes of death from a randomized trial of extended adjuvant endocrine therapy for breast cancer. J Natl Cancer Inst 2008;100:252-260.

3. Hanrahan EO, Gonzalez-Angulo AM, Giordano SH, et al. Overall survival and cause-specific mortality of patients with stage T1a,bNOMO breast carcinoma. J Clin Oncol 2007;25:4952-4960.

4. Abdel-Qadir H, Thavendiranathan $\mathrm{P}$, Austin PC, et al. The risk of heart failure and other cardiovascular hospitalizations after early stage breast cancer: a matched cohort study. J Natl Cancer Inst 2019;111:854-862.

5. Armenian $\mathrm{SH}, \mathrm{Xu} \mathrm{L}, \mathrm{Ky} \mathrm{B}$, et al. Cardiovascular disease among survivors of adult-onset cancer: a community-based retrospective cohort study. J Clin Oncol 2016;34:1122-1130.

6. Boekel NB, Schaapveld M, Gietema JA, et al. Cardiovascular disease risk in a large, population-based cohort of breast cancer survivors. Int J Radiat Oncol Biol Phys 2016;94:1061-1072.

7. Boerman LM, Berendsen AJ, van der Meer P, et al. Long-term follow-up for cardiovascular disease after chemotherapy and/or radiotherapy for breast cancer in an unselected population. Support Care Cancer 2014;22 1949-1958.

8. Brand JS, Hedayati E, Bhoo-Pathy N, et al. Time-dependent risk and predictors of venous thromboembolism in breast cancer patients: a population-based cohort study. Cancer 2017;123:468-475.

9. Chang JS, Shin J, Park EC, et al. Risk of cardiac disease after adjuvant radiation therapy among breast cancer survivors. Breast 2019;43:48-54.

10. Cronin-Fenton DP, Søndergaard F, Pedersen LA, et al. Hospitalisation for venous thromboembolism in cancer patients and the general population: a population-based cohort study in Denmark, 1997-2006. Br J Cancer 2010;103:947-953.

11. Jordan JH, Thwin SS, Lash TL, et al. Incident comorbidities and all-cause mortality among 5-year survivors of stage I and II breast cancer diagnosed at age 65 or older: a prospective-matched cohort study. Breast Cancer Res Treat 2014;146:401-409. 
12. Kero AE, Järvelä LS, Arola $M$, et al. Cardiovascular morbidity in long-term survivors of early-onset cancer: a population-based study. Int J Cancer 2014;134:664-673.

13. Strongman H, Gadd S, Matthews A, et al. Medium and long-term risks of specific cardiovascular diseases in survivors of 20 adult cancers: a population-based cohort study using multiple linked UK electronic health records databases. Lancet 2019;394:1041-1054.

14. National Cancer Institute. Overview of the SEER Program. Accessed October 20, 2020. Available at: https://seer.cancer.gov/about/overview.html

15. Warren JL, Klabunde CN, Schrag D, et al. Overview of the SEERMedicare data: content, research applications, and generalizability to the United States elderly population. Med Care 2002;40(8 Suppl) IV-3-18.

16. Klabunde CN, Potosky AL, Legler JM, et al. Development of a comorbidity index using physician claims data. J Clin Epidemiol 2000;53: 1258-1267.

17. Royston P, Parmar MK. Flexible parametric proportional-hazards and proportional-odds models for censored survival data, with application to prognostic modelling and estimation of treatment effects. Stat Med 2002; 21:2175-2197.

18. Benjamin EJ, Muntner P, Alonso A, et al. Heart disease and stroke statistics-2019 update: a report from the American Heart Association. Circulation 2019;139:e56-528.

19. Macacu A, Autier P, Boniol M, et al. Active and passive smoking and risk of breast cancer: a meta-analysis. Breast Cancer Res Treat 2015;154: 213-224.

20. Bagnardi $\mathrm{V}$, Rota M, Botteri E, et al. Alcohol consumption and site-specific cancer risk: a comprehensive dose-response meta-analysis. $\mathrm{Br} \mathrm{J}$ Cancer 2015; 112:580-593.

21. Zhou Y, Zhao H, Peng C. Association of sedentary behavior with the risk of breast cancer in women: update meta-analysis of observational studies. Ann Epidemiol 2015;25:687-697.

22. Agnoli C, Grioni S, Sieri S, et al. Metabolic syndrome and breast cancer risk: a case-cohort study nested in a multicentre Italian cohort. PLoS One 2015;10:e0128891.

23. Poirier P, Giles TD, Bray GA, et al. Obesity and cardiovascular disease: pathophysiology, evaluation, and effect of weight loss: an update of the 1997 American Heart Association Scientific Statement on Obesity and Heart Disease from the Obesity Committee of the Council on Nutrition, Physical Activity, and Metabolism. Circulation 2006;113: 898-918.

24. Ronksley PE, Brien SE, Turner BJ, et al. Association of alcohol consumption with selected cardiovascular disease outcomes: a systematic review and meta-analysis. BMJ 2011;342:d671.

25. Huxley RR, Woodward M. Cigarette smoking as a risk factor for coronary heart disease in women compared with men: a systematic review and meta-analysis of prospective cohort studies. Lancet $2011 ; 378$ : 1297-1305.

26. Chomistek AK, Manson JE, Stefanick ML, et al. Relationship of sedentary behavior and physical activity to incident cardiovascular disease: results from the Women's Health Initiative. J Am Coll Cardiol 2013:61: 2346-2354

27. Katzmarzyk PT, Church TS, Craig CL, et al. Sitting time and mortality from all causes, cardiovascular disease, and cancer. Med Sci Sports Exerc 2009; 41:998-1005.

28. Swain SM, Whaley FS, Ewer MS. Congestive heart failure in patients treated with doxorubicin: a retrospective analysis of three trials. Cancer 2003;97:2869-2879.

29. Hochster H, Wasserheit C, Speyer J. Cardiotoxicity and cardioprotection during chemotherapy. Curr Opin Oncol 1995;7:304-309.

30. Guglin M, Aljayeh M, Saiyad S, et al. Introducing a new entity: chemotherapy-induced arrhythmia. Europace 2009;11:1579-1586.

31. Ewer MS, Vooletich MT, Durand JB, et al. Reversibility of trastuzumabrelated cardiotoxicity: new insights based on clinical course and response to medical treatment. J Clin Oncol 2005;23:7820-7826.

32. Meyer CC, Calis KA, Burke LB, et al. Symptomatic cardiotoxicity associated with 5-fluorouracil. Pharmacotherapy 1997;17:729-736.

33. Van Cutsem E, Hoff PM, Blum JL, et al. Incidence of cardiotoxicity with the oral fluoropyrimidine capecitabine is typical of that reported with 5-fluorouracil. Ann Oncol 2002;13:484-485.

34. Kosmas C, Kallistratos MS, Kopterides P, et al. Cardiotoxicity of fluoropyrimidines in different schedules of administration: a prospective study. J Cancer Res Clin Oncol 2008;134:75-82.

35. Layoun ME, Wickramasinghe CD, Peralta MV, et al. Fluoropyrimidineinduced cardiotoxicity: manifestations, mechanisms, and management. Curr Oncol Rep 2016;18:35.

36. Matthews A, Stanway S, Farmer RE, et al. Long term adjuvant endocrine therapy and risk of cardiovascular disease in female breast cancer survivors: systematic review. BMJ 2018;363:k3845.

37. Khosrow-Khavar F, Filion KB, Al-Qurashi S, et al. Cardiotoxicity of aromatase inhibitors and tamoxifen in postmenopausal women with breast cancer: a systematic review and meta-analysis of randomized controlled trials. Ann Oncol 2017;28:487-496.

38. Khosrow-Khavar F, Filion KB, Bouganim N, et al. Aromatase inhibitors and the risk of cardiovascular outcomes in women with breast cancer: a population-based cohort study. Circulation 2020;141: 549-559.

39. Darby SC, Ewertz M, McGale P, et al. Risk of ischemic heart disease in women after radiotherapy for breast cancer. N Engl J Med 2013;368: 987-998.

40. Lundqvist A, Andersson E, Ahlberg I, et al. Socioeconomic inequalities in breast cancer incidence and mortality in Europe-a systematic review and meta-analysis. Eur J Public Health 2016;26:804-813.

41. Liu K, Zhang W, Dai Z, et al. Association between body mass index and breast cancer risk: evidence based on a dose-response meta-analysis. Cancer Manag Res 2018;10:143-151.

42. Bhaskaran K, Douglas I, Forbes $\mathrm{H}$, et al. Body-mass index and risk of 22 specific cancers: a population-based cohort study of 5.24 million UK adults. Lancet 2014;384:755-765. 
Supplemental online content for:

\section{Risk of Cardiovascular Diseases Among Older Breast Cancer Survivors in the United States: A Matched Cohort Study}

Anthony A. Matthews, PhD; Sharon Peacock Hinton, MPA; Susannah Stanway, MD; Alexander R. Lyon, PhD; Liam Smeeth, PhD; Krishnan Bhaskaran, PhD; and Jennifer L. Lund, PhD

J Natl Compr Canc Netw 2021;19(3):275-284

eTable 1: ICD-9 and CPT/HCPCS Codes Used to Identify Cardiovascular Disease Outcomes of Interest

eTable 2: Adjusted HRs for Cardiovascular Risk, Stratified by Time Since Index Date, Including Time Up Until 90 Days After Index

eTable 3: Adjusted HRs for Cardiovascular Risk, Stratified by Race/Ethnicity

eTable 4: Adjusted HRs for Cardiovascular Risk, Stratified by Cardiovascular Disease Before Diagnosis

eTable 5: Adjusted HRs for Cardiovascular Risk, Stratified by Current Age

eTable 6: HRs for Cardiovascular Risk, Stratified by Cancer Stage

eTable 7: HRs for Cardiovascular Risk, Stratified by Grade

eTable 8: HRs for Cardiovascular Risk, Stratified by ER/PR Status

eTable 9: Rates, Rate Difference, and HRs for Cardiovascular Risk, Using Only Inpatient Claims to Identify

Cardiovascular Outcomes 


\section{eTable 1. ICD-9 and CPT/HCPCS Codes Used to Identify Cardiovascular Disease Outcomes of Interest}

\section{Outcomes}

Angina

Myocardial infarction

Revascularization procedures
ICD-9 Diagnosis and Procedure Codes

$411.1,413.1,413.9$

$410.11,410.01,410.31,410.21,410.41$,

$410.81,410.51,410.61,410.91,410.71$

$36.0 \times, 36.1 \times, 36.2,36.3$

\section{CPT/HCPCS Codes}

$33140,33510,33511,33512,33513,33514$ $33516,33517,33518,33519,33521,33522$ $33523,33533,33534,33535,33536,92920$, $92924,92928,92933,92937,92941,92943$, 92980, 92981, 92982, 92984, 92995, 92996, 92997, 92998
Sudden cardiac arrest

Stroke (hemorrhagenic and ischemic)

Arrhythmia

Deep venous thromboembolism

Pulmonary embolism

Heart failure
427.5

$430 . \times, 431 . \times 4321,432.0,432.9,433.91$

433.21, 433.01, 433.11, 433.31, 433.81,

$434.01,434 . \times, 435.0,435.1,435.3,435.8$,

$435.9,436 . \times$

$427.31,427.32,427.41,427.42,427.61,427.0$ $427.69,427.60,427.81,427.89,427.9$

$415.1 \times$

415.0, 415.12, 415.13, 415.19

$428.1,428.0,428.20,428.21,428.22,428.23$

$428.30,428.31,428.32,428.33,428.40$,

$428.41,428.42,428.43,428.9414 .8,425.4$,

$425.11,425.18,425.0,425.3,425.5,425.9$,

$425.2,425.8$

Pericarditis

Valvular heart disease

$420.91,420.90,420.99,423.1,423.2,423.0$

423.9, 423.3, 423.8, 420.0

$394.0,394.1,394.2,394.9,395.0,395.1,395.2$,

$395.9,397.0,396.0,396.1,396.2,396.3,397.9$

$396.8,396.9,424.0,424.1,424.2,424.3$ 


\section{eTable 2. Adjusted HRs for Cardiovascular Risk, Stratified by Time Since Index Date, Including Time Up Until} 90 Days After Index

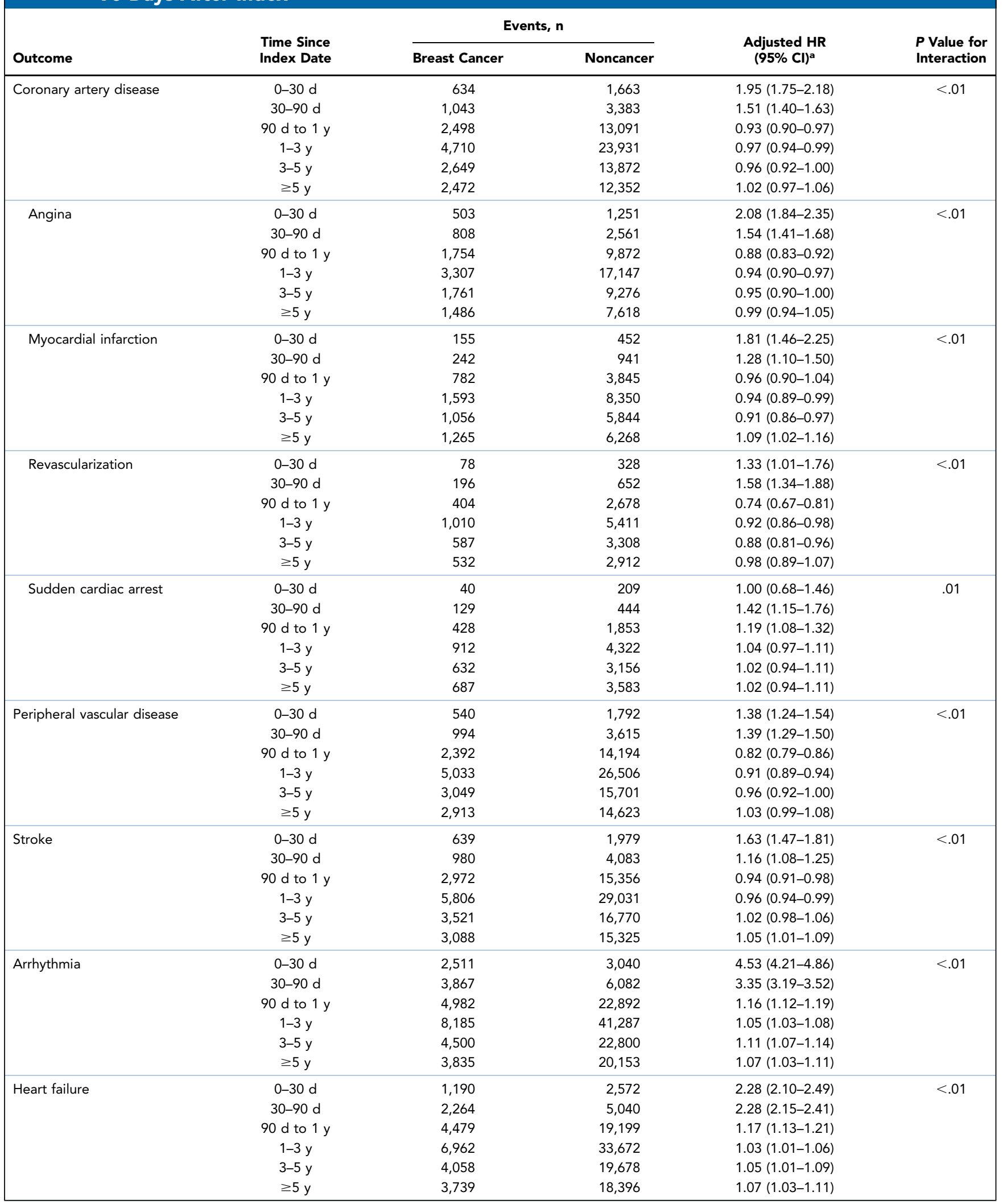




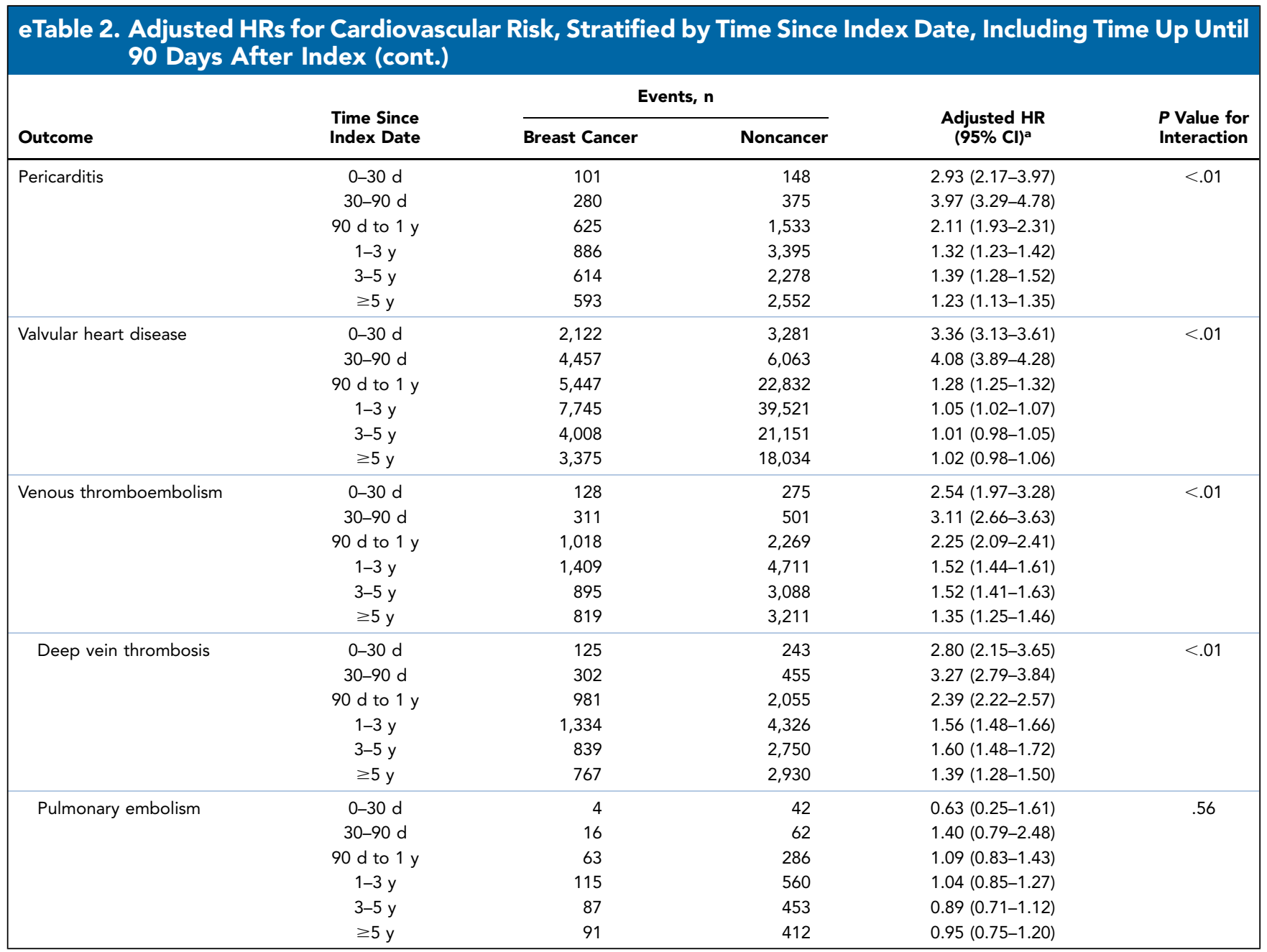

Abbreviation: $H R$, hazard ratio.

aAdjusted for age, SEER region, time since index, current year, rheumatoid arthritis, chronic kidney disease, hypertension, diabetes, and any other cardiovascular disease (other than the disease of interest). 


\section{eTable 3. Adjusted HRs for Cardiovascular Risk,} Stratified by Race/Ethnicity

\begin{tabular}{|c|c|c|c|}
\hline Outcome & $\begin{array}{l}\text { Race/ } \\
\text { Ethnicity }\end{array}$ & $\begin{array}{c}\text { Adjusted HR } \\
(95 \% \mathrm{CI})^{\mathrm{a}}\end{array}$ & $\begin{array}{l}P \text { Value for } \\
\text { Interaction }\end{array}$ \\
\hline \multirow[t]{6}{*}{ CAD } & White & $0.95(0.94-0.97)$ & $<.01$ \\
\hline & Black & $1.08(1.02-1.15)$ & \\
\hline & Other & $0.94(0.81-1.10)$ & \\
\hline & Asian & $1.00(0.88-1.14)$ & \\
\hline & Hispanic & $0.90(0.76-1.06)$ & \\
\hline & $\begin{array}{l}\text { Native } \\
\text { American }\end{array}$ & $1.12(0.74-1.69)$ & \\
\hline \multirow[t]{6}{*}{ Angina } & White & $0.93(0.90-0.95)$ & .62 \\
\hline & Black & $0.99(0.92-1.07)$ & \\
\hline & Other & $0.93(0.77-1.12)$ & \\
\hline & Asian & $0.92(0.79-1.08)$ & \\
\hline & Hispanic & $0.96(0.80-1.15)$ & \\
\hline & $\begin{array}{l}\text { Native } \\
\text { American }\end{array}$ & $1.15(0.70-1.88)$ & \\
\hline \multirow[t]{6}{*}{ Ml } & White & $0.96(0.93-0.99)$ & .04 \\
\hline & Black & $1.10(1.00-1.22)$ & \\
\hline & Other & $1.04(0.81-1.33)$ & \\
\hline & Asian & $1.08(0.87-1.33)$ & \\
\hline & Hispanic & $0.78(0.58-1.05)$ & \\
\hline & $\begin{array}{l}\text { Native } \\
\text { American }\end{array}$ & $1.44(0.66-3.11)$ & \\
\hline \multirow[t]{6}{*}{ Revascularization } & White & $0.88(0.85-0.92)$ & .55 \\
\hline & Black & $0.94(0.81-1.09)$ & \\
\hline & Other & $0.98(0.67-1.41)$ & \\
\hline & Asian & $0.89(0.65-1.23)$ & \\
\hline & Hispanic & $0.78(0.54-1.14)$ & \\
\hline & $\begin{array}{l}\text { Native } \\
\text { American }\end{array}$ & $1.60(0.78-3.27)$ & \\
\hline \multirow[t]{6}{*}{ SCA } & White & $1.03(0.99-1.08)$ & .14 \\
\hline & Black & $1.20(1.07-1.33)$ & \\
\hline & Other & $0.89(0.64-1.22)$ & \\
\hline & Asian & $1.12(0.85-1.47)$ & \\
\hline & Hispanic & $1.07(0.76-1.50)$ & \\
\hline & $\begin{array}{l}\text { Native } \\
\text { American }\end{array}$ & $1.70(0.61-4.73)$ & \\
\hline \multirow[t]{6}{*}{ PVD } & White & $0.93(0.91-0.94)$ & .90 \\
\hline & Black & $0.93(0.87-0.99)$ & \\
\hline & Other & $1.00(0.86-1.17)$ & \\
\hline & Asian & $0.89(0.78-1.02)$ & \\
\hline & Hispanic & $0.91(0.77-1.07)$ & \\
\hline & $\begin{array}{l}\text { Native } \\
\text { American }\end{array}$ & $0.84(0.54-1.31)$ & \\
\hline \multirow[t]{6}{*}{ Stroke } & White & $0.98(0.96-1.00)$ & .08 \\
\hline & Black & $1.01(0.95-1.07)$ & \\
\hline & Other & $0.98(0.86-1.12)$ & \\
\hline & Asian & $1.00(0.89-1.13)$ & \\
\hline & Hispanic & $1.24(1.06-1.45)$ & \\
\hline & $\begin{array}{l}\text { Native } \\
\text { American }\end{array}$ & $0.96(0.66-1.42)$ & \\
\hline \multirow[t]{6}{*}{ Arrhythmia } & White & $1.08(1.07-1.10)$ & .14 \\
\hline & Black & $1.09(1.04-1.15)$ & \\
\hline & Other & $1.09(0.97-1.22)$ & \\
\hline & Asian & $1.20(1.08-1.33)$ & \\
\hline & Hispanic & $1.15(1.00-1.32)$ & \\
\hline & $\begin{array}{l}\text { Native } \\
\text { American }\end{array}$ & $0.74(0.51-1.07)$ & \\
\hline
\end{tabular}

(continued)

\section{eTable 3. Adjusted HRs for Cardiovascular Risk,} Stratified by Race/Ethnicity (cont.)

\begin{tabular}{|c|c|c|c|}
\hline Outcome & $\begin{array}{l}\text { Race/ } \\
\text { Ethnicity }\end{array}$ & $\begin{array}{c}\text { Adjusted HR } \\
(95 \% \mathrm{CI})^{\mathrm{a}}\end{array}$ & $\begin{array}{l}P \text { Value for } \\
\text { Interaction }\end{array}$ \\
\hline \multirow[t]{6}{*}{ Heart failure } & White & $1.07(1.05-1.09)$ & .35 \\
\hline & Black & $1.09(1.03-1.15)$ & \\
\hline & Other & $1.05(0.92-1.20)$ & \\
\hline & Asian & $1.08(0.97-1.20)$ & \\
\hline & Hispanic & $1.27(1.09-1.47)$ & \\
\hline & $\begin{array}{l}\text { Native } \\
\text { American }\end{array}$ & $1.24(0.82-1.87)$ & \\
\hline \multirow[t]{6}{*}{ Pericarditis } & White & $1.42(1.36-1.49)$ & .46 \\
\hline & Black & $1.48(1.30-1.69)$ & \\
\hline & Other & $1.43(0.96-2.15)$ & \\
\hline & Asian & $1.71(1.27-2.30)$ & \\
\hline & Hispanic & $1.50(1.00-2.26)$ & \\
\hline & $\begin{array}{l}\text { Native } \\
\text { American }\end{array}$ & $0.37(0.08-1.74)$ & \\
\hline \multirow[t]{6}{*}{ VHD } & White & $1.08(1.07-1.10)$ & .39 \\
\hline & Black & $1.12(1.06-1.18)$ & \\
\hline & Other & $1.23(1.09-1.38)$ & \\
\hline & Asian & $1.10(0.99-1.22)$ & \\
\hline & Hispanic & $1.09(0.94-1.27)$ & \\
\hline & $\begin{array}{l}\text { Native } \\
\text { American }\end{array}$ & $1.09(0.78-1.53)$ & \\
\hline \multirow[t]{6}{*}{ VTE } & White & $1.58(1.52-1.64)$ & .02 \\
\hline & Black & $1.83(1.65-2.04)$ & \\
\hline & Other & $2.41(1.71-3.39)$ & \\
\hline & Asian & $1.49(1.09-2.05)$ & \\
\hline & Hispanic & $1.53(1.05-2.24)$ & \\
\hline & $\begin{array}{l}\text { Native } \\
\text { American }\end{array}$ & $2.15(0.83-5.57)$ & \\
\hline \multirow[t]{6}{*}{ DVT } & White & $1.65(1.59-1.71)$ & .03 \\
\hline & Black & $1.84(1.65-2.05)$ & \\
\hline & Other & $2.84(1.96-4.10)$ & \\
\hline & Asian & $1.54(1.09-2.18)$ & \\
\hline & Hispanic & $1.62(1.11-2.36)$ & \\
\hline & $\begin{array}{l}\text { Native } \\
\text { American }\end{array}$ & $2.16(0.84-5.56)$ & \\
\hline \multirow[t]{6}{*}{ PE } & White & $0.95(0.84-1.07)$ & .15 \\
\hline & Black & $1.32(0.91-1.93)$ & \\
\hline & Other & $0.37(0.10-1.34)$ & \\
\hline & Asian & $1.56(0.79-3.06)$ & \\
\hline & Hispanic & $1.48(0.21-10.50)$ & \\
\hline & $\begin{array}{l}\text { Native } \\
\text { American }\end{array}$ & $0.95(0.84-1.07)$ & \\
\hline
\end{tabular}

Abbreviations: CAD, coronary artery disease; DVT, deep vein thrombosis; $\mathrm{HR}$, hazard ratio; MI, myocardial infarction; $\mathrm{PE}$, pulmonary embolism; $\mathrm{PVD}$, peripheral vascular disease; SCA, sudden cardiac arrest; VHD, valvular heart disease; VTE, venous thromboembolism.

aAdjusted for age, SEER region, time since index, current year, rheumatoid arthritis, chronic kidney disease, hypertension, diabetes, and any other cardiovascular disease (other than the disease of interest). 


\begin{tabular}{|c|c|c|c|}
\hline \multicolumn{4}{|c|}{$\begin{array}{l}\text { eTable 4. Adjusted HRs for Cardiovascular Risk, } \\
\text { Stratified by Cardiovascular Disease } \\
\text { Before Diagnosis }\end{array}$} \\
\hline Outcome & $\begin{array}{c}\text { CVD Before } \\
\text { Diagnosis }\end{array}$ & $\begin{array}{c}\text { Adjusted HR } \\
(95 \% \mathrm{CI})^{\mathrm{a}}\end{array}$ & $\begin{array}{l}P \text { Value for } \\
\text { Interaction }\end{array}$ \\
\hline \multirow[t]{2}{*}{ CAD } & No & $0.98(0.96-1.01)$ & .05 \\
\hline & Yes & $0.94(0.91-0.97)$ & \\
\hline \multirow[t]{2}{*}{ Angina } & No & $0.94(0.91-0.97)$ & .45 \\
\hline & Yes & $0.92(0.89-0.96)$ & \\
\hline \multirow[t]{2}{*}{$\mathrm{Ml}$} & No & $1.00(0.96-1.04)$ & .05 \\
\hline & Yes & $0.94(0.89-0.98)$ & \\
\hline \multirow[t]{2}{*}{ Revascularization } & No & $0.88(0.83-0.93)$ & .66 \\
\hline & Yes & $0.90(0.84-0.96)$ & \\
\hline \multirow[t]{2}{*}{ SCA } & No & $1.12(1.05-1.18)$ & .01 \\
\hline & Yes & $0.99(0.93-1.05)$ & \\
\hline \multirow[t]{2}{*}{ PVD } & No & $0.95(0.92-0.97)$ & .01 \\
\hline & Yes & $0.89(0.87-0.92)$ & \\
\hline \multirow[t]{2}{*}{ Stroke } & No & $1.00(0.98-1.02)$ & .02 \\
\hline & Yes & $0.96(0.93-0.98)$ & \\
\hline \multirow[t]{2}{*}{ Arrhythmia } & No & $1.11(1.09-1.13)$ & $<.01$ \\
\hline & Yes & $1.04(1.01-1.07)$ & \\
\hline \multirow[t]{2}{*}{ Heart failure } & No & $1.11(1.09-1.14)$ & $<.01$ \\
\hline & Yes & $0.99(0.96-1.02)$ & \\
\hline \multirow[t]{2}{*}{ Pericarditis } & No & $1.59(1.50-1.68)$ & $<.01$ \\
\hline & Yes & $1.25(1.18-1.34)$ & \\
\hline \multirow[t]{2}{*}{ VHD } & No & $1.11(1.09-1.13)$ & $<.01$ \\
\hline & Yes & $1.04(1.01-1.07)$ & \\
\hline \multirow[t]{2}{*}{ VTE } & No & $1.79(1.71-1.87)$ & $<.01$ \\
\hline & Yes & $1.37(1.30-1.45)$ & \\
\hline \multirow[t]{2}{*}{ DVT } & No & $1.85(1.76-1.94)$ & $<.01$ \\
\hline & Yes & $1.44(1.36-1.53)$ & \\
\hline \multirow[t]{2}{*}{ PE } & No & $1.10(0.93-1.30)$ & .07 \\
\hline & Yes & $0.88(0.74-1.03)$ & \\
\hline
\end{tabular}

Abbreviations: $C A D$, coronary artery disease; $C V D$, cardiovascular disease; DVT, deep vein thrombosis; HR, hazard ratio; MI, myocardial infarction; PE, pulmonary embolism; PVD, peripheral vascular disease; SCA, sudden cardiac arrest: VHD, valvular heart disease; VTE, venous thromboembolism. ${ }^{a}$ Adjusted for age, SEER region, time since index, current year, rheumatoid arthritis, chronic kidney disease, hypertension, diabetes, and any other CVD (other than the disease of interest).

\begin{tabular}{|c|c|c|c|}
\hline Outcome & $\begin{array}{l}\text { Current } \\
\text { Age, y }\end{array}$ & $\begin{array}{c}\text { Adjusted HR } \\
(95 \% \mathrm{Cl})^{\mathrm{a}}\end{array}$ & $\begin{array}{l}P \text { Value for } \\
\text { Interaction }\end{array}$ \\
\hline \multirow[t]{3}{*}{ CAD } & $66-75$ & $0.95(0.92-0.98)$ & .44 \\
\hline & $>75-85$ & $0.97(0.94-0.99)$ & \\
\hline & $>85$ & $0.98(0.94-1.02)$ & \\
\hline \multirow[t]{3}{*}{ Angina } & $66-75$ & $0.88(0.84-0.91)$ & $<.01$ \\
\hline & $>75-85$ & $0.94(0.91-0.97)$ & \\
\hline & $>85$ & $1.02(0.97-1.07)$ & \\
\hline \multirow[t]{3}{*}{ MI } & $66-75$ & $1.01(0.95-1.08)$ & 28 \\
\hline & $>75-85$ & $0.95(0.91-0.99)$ & \\
\hline & $>85$ & $0.98(0.93-1.03)$ & \\
\hline \multirow[t]{3}{*}{ Revascularization } & $66-75$ & $0.81(0.75-0.87)$ & .01 \\
\hline & $>75-85$ & $0.92(0.87-0.97)$ & \\
\hline & $>85$ & $0.96(0.87-1.07)$ & \\
\hline \multirow[t]{3}{*}{ SCA } & $66-75$ & $1.23(1.13-1.34)$ & $<.01$ \\
\hline & $>75-85$ & 1.05 (1.00-1.12) & \\
\hline & $>85$ & $0.95(0.88-1.02)$ & \\
\hline \multirow[t]{3}{*}{ PVD } & $66-75$ & $0.91(0.88-0.95)$ & .53 \\
\hline & $>75-85$ & $0.93(0.90-0.95)$ & \\
\hline & $>85$ & $0.94(0.91-0.97)$ & \\
\hline \multirow[t]{3}{*}{ Stroke } & $66-75$ & $1.01(0.97-1.04)$ & .06 \\
\hline & $>75-85$ & $0.99(0.97-1.01)$ & \\
\hline & $>85$ & $0.95(0.92-0.98)$ & \\
\hline \multirow[t]{3}{*}{ Arrhythmia } & $66-75$ & $1.15(1.12-1.18)$ & $<.01$ \\
\hline & $>75-85$ & 1.07 (1.05-1.09) & \\
\hline & $>85$ & $1.04(1.00-1.07)$ & \\
\hline \multirow[t]{3}{*}{ Heart failure } & $66-75$ & $1.24(1.21-1.28)$ & $<.01$ \\
\hline & $>75-85$ & $1.02(1.00-1.04)$ & \\
\hline & $>85$ & $1.01(0.98-1.04)$ & \\
\hline \multirow[t]{3}{*}{ Pericarditis } & $66-75$ & $1.80(1.67-1.93)$ & $<.01$ \\
\hline & $>75-85$ & 1.37 (1.29-1.45) & \\
\hline & $>85$ & $1.18(1.08-1.30)$ & \\
\hline \multirow[t]{3}{*}{ VHD } & $66-75$ & $1.23(1.20-1.27)$ & $<.01$ \\
\hline & $>75-85$ & $1.03(1.01-1.06)$ & \\
\hline & $>85$ & $1.01(0.98-1.05)$ & \\
\hline \multirow[t]{3}{*}{ VTE } & $66-75$ & $2.12(2.00-2.25)$ & $<.01$ \\
\hline & $>75-85$ & $1.48(1.41-1.56)$ & \\
\hline & $>85$ & $1.36(1.26-1.46)$ & \\
\hline \multirow[t]{3}{*}{ DVT } & $66-75$ & $2.23(2.10-2.37)$ & $<.01$ \\
\hline & $>75-85$ & $1.54(1.47-1.62)$ & \\
\hline & $>85$ & $1.40(1.30-1.51)$ & \\
\hline \multirow[t]{3}{*}{ PE } & $66-75$ & $1.10(0.89-1.37)$ & .42 \\
\hline & $>75-85$ & $0.92(0.79-1.08)$ & \\
\hline & $>85$ & $0.98(0.77-1.24)$ & \\
\hline
\end{tabular}

Abbreviations: CAD, coronary artery disease; DVT, deep vein thrombosis; $H R$, hazard ratio; MI, myocardial infarction; PE, pulmonary embolism; PVD, peripheral vascular disease; SCA, sudden cardiac arrest; VHD, valvular heart disease; VTE, venous thromboembolism.

${ }^{a}$ Adjusted for age, SEER region, time since index, current year, rheumatoid arthritis, chronic kidney disease, hypertension, diabetes, and any other cardiovascular disease (other than the disease of interest). 


\begin{tabular}{|c|c|c|c|}
\hline \multicolumn{4}{|c|}{$\begin{array}{l}\text { eTable 6. HRs for Cardiovascular Risk, Stratified by } \\
\text { Cancer Stage }\end{array}$} \\
\hline Outcome & $\begin{array}{l}\text { Cancer } \\
\text { Stage }\end{array}$ & $\begin{array}{c}\text { Unadjusted HR } \\
(95 \% \mathrm{Cl})\end{array}$ & $\begin{array}{c}\text { Adjusted HRa } \\
(95 \% \mathrm{Cl})\end{array}$ \\
\hline \multirow[t]{3}{*}{ CAD } & 1 & $0.91(0.89-0.93)$ & $0.90(0.88-0.92)$ \\
\hline & $\|$ & $1.02(0.99-1.06)$ & $1.00(0.97-1.04)$ \\
\hline & III & $1.22(1.16-1.29)$ & $1.23(1.16-1.30)$ \\
\hline \multirow[t]{3}{*}{ Angina } & 1 & $0.94(0.91-0.96)$ & $0.93(0.90-0.96)$ \\
\hline & ॥I & $0.94(0.90-0.98)$ & $0.92(0.89-0.96)$ \\
\hline & III & $1.01(0.95-1.09)$ & $1.01(0.94-1.09)$ \\
\hline \multirow[t]{3}{*}{ Ml } & 1 & $0.87(0.84-0.91)$ & $0.87(0.84-0.91)$ \\
\hline & ॥I & $1.06(1.00-1.11)$ & $1.03(0.98-1.09)$ \\
\hline & III & $1.34(1.23-1.45)$ & $1.35(1.24-1.48)$ \\
\hline \multirow[t]{3}{*}{ Revascularization } & 1 & $0.90(0.85-0.94)$ & $0.90(0.85-0.94)$ \\
\hline & II & $0.89(0.83-0.95)$ & $0.88(0.82-0.94)$ \\
\hline & III & $0.88(0.78-1.01)$ & $0.88(0.77-1.00)$ \\
\hline \multirow[t]{3}{*}{ SCA } & 1 & $0.85(0.80-0.90)$ & $0.84(0.80-0.89)$ \\
\hline & ॥ & $1.20(1.13-1.28)$ & $1.20(1.12-1.28)$ \\
\hline & III & $1.74(1.57-1.93)$ & $1.85(1.66-2.05)$ \\
\hline \multirow[t]{3}{*}{ PVD } & I & $0.92(0.90-0.94)$ & $0.91(0.89-0.93)$ \\
\hline & II & $0.95(0.92-0.98)$ & $0.93(0.90-0.96)$ \\
\hline & III & $1.03(0.98-1.09)$ & $1.04(0.98-1.10)$ \\
\hline \multirow[t]{3}{*}{ Stroke } & 1 & $0.94(0.92-0.97)$ & $0.94(0.92-0.96)$ \\
\hline & II & $1.03(1.00-1.06)$ & $1.02(0.99-1.05)$ \\
\hline & III & $1.17(1.12-1.24)$ & $1.17(1.11-1.23)$ \\
\hline \multirow[t]{3}{*}{ Arrhythmia } & I & $1.03(1.01-1.05)$ & $1.03(1.01-1.05)$ \\
\hline & II & $1.13(1.10-1.16)$ & $1.13(1.10-1.15)$ \\
\hline & III & $1.34(1.28-1.40)$ & $1.35(1.29-1.42)$ \\
\hline \multirow[t]{3}{*}{ Heart failure } & 1 & $0.97(0.95-0.99)$ & $0.95(0.93-0.97)$ \\
\hline & II & $1.18(1.15-1.21)$ & $1.18(1.14-1.21)$ \\
\hline & III & $1.53(1.46-1.60)$ & $1.56(1.49-1.64)$ \\
\hline \multirow[t]{3}{*}{ Pericarditis } & I & $1.21(1.14-1.28)$ & $1.21(1.15-1.28)$ \\
\hline & ॥ & $1.52(1.42-1.62)$ & $1.54(1.44-1.65)$ \\
\hline & III & $2.47(2.22-2.76)$ & $2.59(2.31-2.90)$ \\
\hline \multirow[t]{3}{*}{ VHD } & 1 & $1.03(1.01-1.05)$ & $1.02(1.00-1.04)$ \\
\hline & II & $1.14(1.11-1.17)$ & $1.14(1.11-1.17)$ \\
\hline & III & $1.38(1.31-1.44)$ & $1.38(1.32-1.45)$ \\
\hline \multirow[t]{3}{*}{ VTE } & I & $1.36(1.30-1.43)$ & $1.37(1.31-1.43)$ \\
\hline & II & $1.70(1.61-1.80)$ & $1.73(1.63-1.83)$ \\
\hline & III & $2.67(2.44-2.92)$ & $2.79(2.54-3.07)$ \\
\hline \multirow[t]{3}{*}{ DVT } & 1 & $1.40(1.33-1.46)$ & $1.41(1.34-1.48)$ \\
\hline & ॥I & $1.79(1.70-1.90)$ & $1.82(1.72-1.93)$ \\
\hline & III & $2.80(2.55-3.08)$ & $2.92(2.65-3.22)$ \\
\hline \multirow[t]{3}{*}{ PE } & I & $1.08(0.95-1.24)$ & $1.00(0.87-1.16)$ \\
\hline & II & $0.86(0.70-1.05)$ & $0.82(0.66-1.02)$ \\
\hline & III & $1.37(1.00-1.89)$ & $1.37(0.97-1.92)$ \\
\hline
\end{tabular}

Abbreviations: CAD, coronary artery disease; DVT, deep vein thrombosis; $\mathrm{HR}$, hazard ratio; MI, myocardial infarction; PE, pulmonary embolism; PVD, peripheral vascular disease; SCA, sudden cardiac arrest; VHD, valvular heart disease; VTE, venous thromboembolism.

${ }^{a}$ Adjusted for age, SEER region, time since index, current year, rheumatoid arthritis, chronic kidney disease, hypertension, diabetes, and any other cardiovascular disease (other than the disease of interest).

\begin{tabular}{|c|c|c|c|}
\hline \multicolumn{4}{|c|}{$\begin{array}{l}\text { eTable 7. HRs for Cardiovascular Risk, Stratified by } \\
\text { Grade }\end{array}$} \\
\hline Outcome & Grade & $\begin{array}{c}\text { Unadjusted HR } \\
(95 \% \mathrm{Cl})\end{array}$ & $\begin{array}{c}\text { Adjusted HR }{ }^{a} \\
(95 \% \mathrm{Cl})\end{array}$ \\
\hline \multirow[t]{3}{*}{ CAD } & 1 & $0.91(0.88-0.94)$ & $0.90(0.87-0.94)$ \\
\hline & 2 & $0.96(0.93-0.98)$ & $0.95(0.92-0.97)$ \\
\hline & 3 & $1.07(1.03-1.11)$ & $1.05(1.01-1.09)$ \\
\hline \multirow[t]{3}{*}{ Angina } & 1 & $0.91(0.87-0.95)$ & $0.91(0.87-0.95)$ \\
\hline & 2 & $0.93(0.90-0.96)$ & $0.92(0.89-0.95)$ \\
\hline & 3 & $1.00(0.95-1.04)$ & $0.98(0.94-1.02)$ \\
\hline \multirow[t]{3}{*}{$\mathrm{Ml}$} & 1 & $0.88(0.83-0.93)$ & $0.89(0.83-0.94)$ \\
\hline & 2 & $0.96(0.92-1.01)$ & $0.96(0.91-1.00)$ \\
\hline & 3 & $1.10(1.04-1.16)$ & $1.09(1.02-1.15)$ \\
\hline \multirow[t]{3}{*}{ Revascularization } & 1 & $0.91(0.84-0.99)$ & $0.92(0.85-1.00)$ \\
\hline & 2 & $0.85(0.80-0.90)$ & $0.84(0.79-0.89)$ \\
\hline & 3 & $0.98(0.91-1.06)$ & $0.96(0.89-1.03)$ \\
\hline \multirow[t]{3}{*}{ SCA } & 1 & $0.91(0.83-0.99)$ & $0.92(0.84-1.00)$ \\
\hline & 2 & $1.03(0.97-1.09)$ & $1.02(0.96-1.09)$ \\
\hline & 3 & $1.26(1.17-1.35)$ & $1.26(1.17-1.35)$ \\
\hline \multirow[t]{3}{*}{ PVD } & 1 & $0.91(0.88-0.94)$ & $0.91(0.88-0.94)$ \\
\hline & 2 & $0.93(0.91-0.96)$ & $0.92(0.90-0.95)$ \\
\hline & 3 & $0.97(0.93-1.00)$ & $0.94(0.91-0.97)$ \\
\hline \multirow[t]{3}{*}{ Stroke } & 1 & $0.99(0.96-1.02)$ & $0.98(0.95-1.02)$ \\
\hline & 2 & $0.97(0.94-0.99)$ & $0.96(0.94-0.98)$ \\
\hline & 3 & $1.04(1.01-1.08)$ & $1.03(0.99-1.06)$ \\
\hline \multirow[t]{3}{*}{ Arrhythmia } & 1 & $1.06(1.03-1.09)$ & $1.06(1.03-1.09)$ \\
\hline & 2 & $1.06(1.04-1.08)$ & $1.06(1.04-1.08)$ \\
\hline & 3 & $1.16(1.13-1.20)$ & $1.15(1.12-1.19)$ \\
\hline \multirow[t]{3}{*}{ Heart failure } & 1 & $0.96(0.93-0.99)$ & $0.94(0.91-0.97)$ \\
\hline & 2 & $1.05(1.03-1.07)$ & $1.04(1.02-1.07)$ \\
\hline & 3 & $1.27(1.23-1.31)$ & $1.25(1.22-1.29)$ \\
\hline \multirow[t]{3}{*}{ Pericarditis } & 1 & $1.18(1.08-1.28)$ & $1.20(1.10-1.31)$ \\
\hline & 2 & $1.32(1.25-1.41)$ & $1.34(1.26-1.42)$ \\
\hline & 3 & $1.81(1.68-1.95)$ & $1.84(1.70-1.98)$ \\
\hline \multirow[t]{3}{*}{ VHD } & 1 & $1.00(0.97-1.03)$ & $1.00(0.97-1.03)$ \\
\hline & 2 & $1.08(1.05-1.10)$ & $1.07(1.05-1.10)$ \\
\hline & 3 & $1.24(1.21-1.28)$ & $1.23(1.20-1.27)$ \\
\hline \multirow[t]{3}{*}{ VTE } & 1 & $1.29(1.21-1.39)$ & $1.30(1.21-1.40)$ \\
\hline & 2 & $1.54(1.47-1.62)$ & $1.57(1.49-1.65)$ \\
\hline & 3 & $1.94(1.82-2.06)$ & $1.95(1.84-2.08)$ \\
\hline \multirow[t]{3}{*}{ DVT } & 1 & $1.33(1.24-1.43)$ & $1.35(1.25-1.45)$ \\
\hline & 2 & $1.59(1.51-1.67)$ & $1.62(1.54-1.71)$ \\
\hline & 3 & $2.05(1.92-2.18)$ & $2.07(1.94-2.20)$ \\
\hline \multirow[t]{3}{*}{ PE } & 1 & $0.94(0.75-1.18)$ & $0.88(0.70-1.11)$ \\
\hline & 2 & $1.14(0.97-1.32)$ & $1.10(0.94-1.30)$ \\
\hline & 3 & $1.00(0.80-1.24)$ & $0.91(0.72-1.16)$ \\
\hline
\end{tabular}

Abbreviations: CAD, coronary artery disease; DVT, deep vein thrombosis; $H R$, hazard ratio; MI, myocardial infarction; PE, pulmonary embolism; PVD, peripheral vascular disease; SCA, sudden cardiac arrest; VHD, valvular heart disease; VTE, venous thromboembolism.

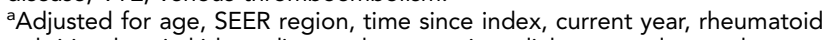
arthritis, chronic kidney disease, hypertension, diabetes, and any other cardiovascular disease (other than the disease of interest). 


\section{eTable 8. HRs for Cardiovascular Risk, Stratified by ER/PR Status}

\begin{tabular}{|c|c|c|c|}
\hline Outcome & $\begin{array}{l}\text { ER/PR } \\
\text { Status }\end{array}$ & $\begin{array}{l}\text { Unadjusted } \\
\text { HR }(95 \% \mathrm{Cl})\end{array}$ & $\begin{array}{l}\text { Adjusted HR } \\
(95 \% \mathrm{Cl})\end{array}$ \\
\hline \multirow[t]{2}{*}{ Coronary artery disease } & Positive & $0.96(0.94-0.98)$ & $0.95(0.93-0.97)$ \\
\hline & Negative & $1.01(0.96-1.07)$ & $1.00(0.95-1.06)$ \\
\hline \multirow[t]{2}{*}{ Angina } & Positive & $0.94(0.91-0.96)$ & $0.93(0.90-0.95)$ \\
\hline & Negative & $0.90(0.85-0.96)$ & $0.89(0.84-0.95)$ \\
\hline \multirow[t]{2}{*}{ Myocardial infarction } & Positive & $0.95(0.92-0.98)$ & $0.94(0.91-0.98)$ \\
\hline & Negative & 1.08 (0.99-1.17) & 1.07 (0.99-1.17) \\
\hline \multirow[t]{2}{*}{ Revascularization } & Positive & $0.88(0.84-0.92)$ & $0.88(0.84-0.92)$ \\
\hline & Negative & $0.91(0.82-1.01)$ & $0.90(0.81-1.00)$ \\
\hline \multirow[t]{2}{*}{ Sudden cardiac arrest } & Positive & $1.01(0.97-1.06)$ & $1.01(0.97-1.06)$ \\
\hline & Negative & $1.21(1.09-1.34)$ & $1.21(1.08-1.34)$ \\
\hline \multirow[t]{2}{*}{ Peripheral vascular disease } & Positive & $0.92(0.91-0.94)$ & $0.91(0.89-0.93)$ \\
\hline & Negative & $0.98(0.93-1.03)$ & $0.97(0.92-1.02)$ \\
\hline \multirow[t]{2}{*}{ Stroke } & Positive & $0.97(0.96-0.99)$ & $0.97(0.95-0.98)$ \\
\hline & Negative & $1.07(1.03-1.12)$ & $1.06(1.01-1.11)$ \\
\hline \multirow[t]{2}{*}{ Arrhythmia } & Positive & 1.07 (1.06-1.09) & $1.07(1.05-1.09)$ \\
\hline & Negative & $1.20(1.16-1.25)$ & $1.21(1.16-1.26)$ \\
\hline \multirow[t]{2}{*}{ Heart failure } & Positive & 1.05 (1.03-1.07) & $1.04(1.02-1.06)$ \\
\hline & Negative & $1.27(1.22-1.32)$ & $1.26(1.21-1.31)$ \\
\hline \multirow[t]{2}{*}{ Pericarditis } & Positive & $1.33(1.27-1.39)$ & $1.34(1.28-1.40)$ \\
\hline & Negative & $2.04(1.85-2.25)$ & $2.08(1.88-2.31)$ \\
\hline \multirow[t]{2}{*}{ Valvular heart disease } & Positive & $1.06(1.04-1.08)$ & $1.06(1.04-1.08)$ \\
\hline & Negative & $1.31(1.26-1.37)$ & $1.31(1.26-1.36)$ \\
\hline \multirow[t]{2}{*}{ Venous thromboembolism } & Positive & $1.51(1.46-1.57)$ & 1.53 (1.48-1.59) \\
\hline & Negative & $2.04(1.88-2.22)$ & $2.06(1.89-2.24)$ \\
\hline \multirow[t]{2}{*}{ Deep vein thrombosis } & Positive & $1.57(1.51-1.63)$ & $1.59(1.53-1.66)$ \\
\hline & Negative & $2.15(1.97-2.34)$ & $2.17(1.99-2.37)$ \\
\hline \multirow[t]{2}{*}{ Pulmonary embolism } & Positive & $1.02(0.91-1.15)$ & $0.96(0.84-1.09)$ \\
\hline & Negative & $1.24(0.95-1.62)$ & $1.28(0.95-1.72)$ \\
\hline
\end{tabular}

Abbreviations: ER, estrogen receptor; HR, hazard ratio; PR, progesterone receptor.

${ }^{a}$ Adjusted for age, SEER region, time since index, current year, rheumatoid arthritis, chronic kidney disease, hypertension, diabetes, and any other cardiovascular disease (other than the disease of interest). 


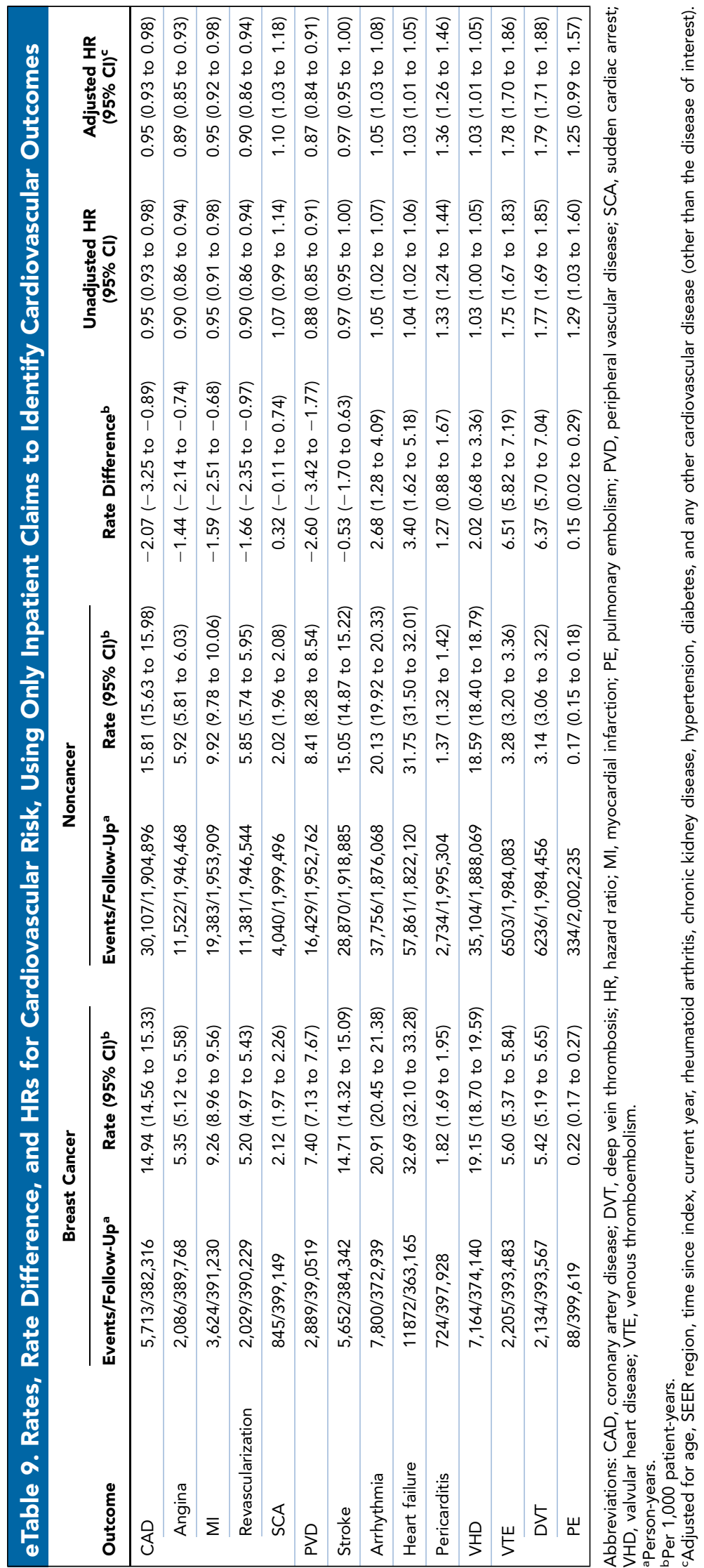

